\title{
CARCEL-PRESIDIO Y JUZGADO DE PUNTA ARENAS: DE LA PREFIGURACIÓN A LA CONFIGURACIÓN DE UN ESPACIO CARCELARIO (1898-2015)
}

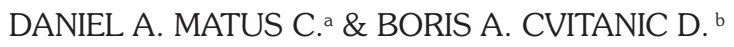

\section{RESUMEN ${ }^{1}$}

Al terminar el siglo XIX e iniciarse el siglo XX el territorio de Magallanes y, en particular, la ciudad de Punta Arenas, se dota de nuevos edificios institucionales entre los que destacan el Juzgado de Letras y la Cárcel-Presidio. A fin de contribuir al conocimiento de lo que hemos denominado complejo penitenciario y judicial, se han realizado una serie de hipótesis en relación a sus diversas configuraciones espaciales, materializadas planimétricamente a partir de fuentes diversas, gráficas y bibliográficas. Para comprender el sentido de las transformaciones, se ha recurrido a la historia de la arquitectura penitenciaria y a documentos históricos que dan luces sobre los derroteros institucionales que movilizaron la reconfiguración permanente de estos edificios de fuerte peso simbólico en la ciudad.

PALABRAS CLAVE: Arquitectura penitenciaria, Punta Arenas, sistema penitenciario

\section{JAIL-PRISON AND COURT OF PUNTA ARENAS: FROM PREFIGURATION TO THE CONFIGURATION OF A PRISON SPACE}

\begin{abstract}
Between the end of the 19th century and the early 20th century, the territory of Magallanes, and particularly Punta Arenas city, was endowed with new institutional buildings, among which there were the Court and the Jail-Prison. To contribute to the knowledge of what we have called penitentiary and judicial complex, we deeply analysed various bibliographic and graphical sources and made hypotheses related to their various spatial configurations suggesting a series of planimetric designs. In order to understand the transformations that happened to this complex, we investigated the history of penitentiary architecture and various historical documents that shed light on the paths

1 Artículo inscrito en proyecto FONDART Regional, modalidad Investigación, Folio No 90502 - 2015 Complejo PenitenciarioJudicial-Policial: Confinamiento y Configuración Espacial de un Patrimonio. Cuyo responsable es Claudia Ojeda A.

a Arquitecto-Urbanista. Académico, Depto. de Arquitectura Universidad de Magallanes, Av. Bulnes 01890, Punta Arenas, Chile. dmatusc@gmail.com

b Dr. Arquitecto. Académico, Depto. de Arquitectura Universidad de Magallanes, Av. Bulnes 01890, Punta Arenas, Chile. cvitanic.boris@gmail.com
\end{abstract}


underlying the permanent reconfiguration of this building that has a strong symbolic weight in the city.

KEY WORDS: prison architecture, Punta Arenas, prison system.

\section{INTRODUCCIÓN}

Comenzado el siglo XX, y tras los cinco lustros transcurridos desde que se iniciara su construcción, a los habitantes de la ciudad de Punta Arenas se les hizo habitual la imagen urbana que el complejo penitenciario y judicial comenzaba a presentar en el centro de la ciudad. En contraste, su interior -como lugar de corrección, de castigo o de vigilancia- permaneció desconocido para quienes no fueron sometidos a encierro y privación de libertad, trabajaron allí o debieron visitarlo -como familiares o abogados-, hasta que a principios del siglo XXI el recinto carcelario se relocalizó en la periferia de la urbe. A partir de ese momento, el edificio adquirió nuevas funciones de tipo cultural que permitieron visitarlo y recorrerlo. Ese desconocimiento se debe, en parte, a razones de seguridad que impiden acceder a representaciones de los recintos penitenciarios y policiales, pero también se debe a que las vicisitudes históricas de los espacios de la reclusión y del espacio carcelario en Chile, se encuentran poco estudiadas si se toman en cuenta las dimensiones urbana y arquitectónica del problema. El complejo penitenciario y judicial de Punta Arenas no es una excepción, no obstante, su localización durante casi un siglo en el centro político, administrativo y religioso de la ciudad, su asociación a las construcciones del Juzgado de Letras, a las residencias del juez y del alcaide de la prisión y su declarado valor patrimonial, hacen de ella un objeto de estudio privilegiado y particular.

$\mathrm{Si}$ se dejan de lado los informes técnicos relacionados con la arquitectura y las condiciones materiales del conjunto de edificios (Arcadis Geotécnica, 2008; Dirección de Bibliotecas, Archivos y Museos, 2014), se evidencia la escasez

2 Decreto MINEDUC N409 del 28.10.2009, que declara Monumento Histórico el edificio de la Dirección Regional de Gendarmería, la Prefectura de Carabineros y la Penitenciaría Local, ubicados en la ciudad de Punta Arenas.

3 En el año 2014, la Dirección de Archivos y Museos (DIBAM) solicitó servicios de diagnóstico y levantamientos críticos de de referencias bibliográficas, que se limitan a publicaciones que consideran los edificios desde un punto de vista histórico y de alcance panorámico (León, 1998; Baeriswyl, 2001; Gendarmería de Chile, 2004; Martinic, 2006; Martinovic, 2006, 2007), sin que existan trabajos específicos sobre la evolución espacial, formal y funcional de los edificios durante los siglos XX y XXI. Finalmente, el conocimiento preliminar de ese complejo, en particular de los edificios de la cárcel-presidio y del juzgado, se funda, en primer lugar, en estudios destinados a dar sustento a la declaratoria de los inmuebles de la cárcel-presidio, del juzgado y de la policía de Punta Arenas como Monumentos Históricos ${ }^{2} y$, en segundo lugar, en informes técnicos que buscaron determinar las características actuales de los inmuebles con miras a rehabilitarlos para acoger a la futura Biblioteca y Archivo Regional de Magallanes ${ }^{3}$.

En el presente trabajo se partió de la idea de que, por su localización central y en un predio pequeño y, considerando las funciones que debió acoger, el complejo penitenciario y judicial de Punta Arenas se vio constantemente sometido a presiones por crecer y transformarse por factores como el aumento de la población penal, su diferenciación por situación procesal, peligrosidad, género, franja etaria o por la adaptación normativa y funcional a requerimientos de las instituciones destinadas a impartir justicia y hacer cumplir las condenas. En consecuencia, se consideró que era posible trazar de manera hipotética las diferentes etapas de construcción y transformaciones de los recintos interiores y de la envolvente del edificio, siendo éstos posteriores a una prefiguración inicial de la que sólo se conoce una de sus elevaciones (Fig. 1), publicada en el Censo Jeneral de Población de 1906 (Navarro, 1908).

los edificios ex Penitenciaria y Gendarmería destinados a generar las bases del Concurso Nacional de Arquitectura Anteproyecto Biblioteca Regional y Archivo Regional de Magallanes. Habilitación y construcción de los Monumentos Históricos ex Penitenciaria y Gendarmería de Punta Arenas cuya convocatoria se abrió el 15 de septiembre de 2014. 
Fig. 1 Elevación principal de conjunto, según proyecto inicial.

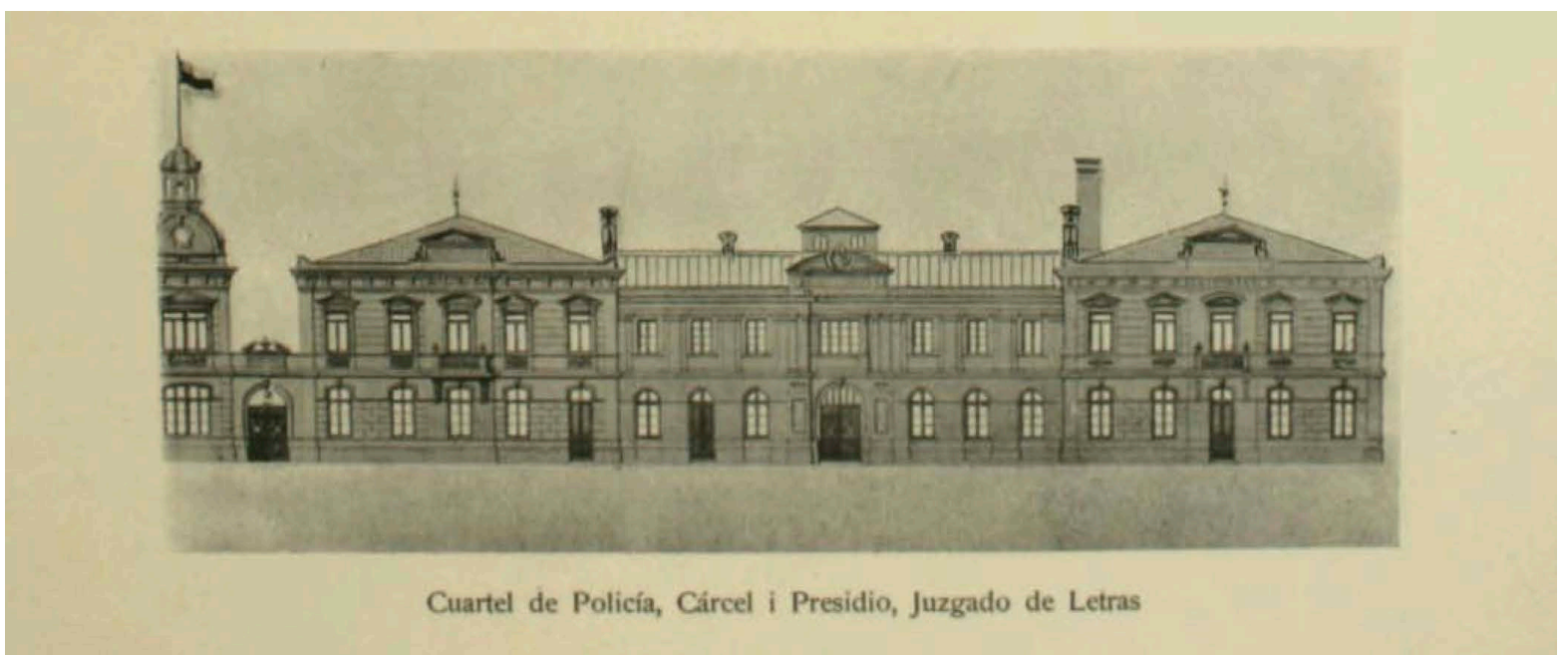

Fuente: Navarro, 1908, p.30.

Nuestra contribución buscó establecer las diferentes etapas de configuración espacial, formal y funcional del complejo penitenciario y judicial de Punta Arenas. Para ello se tomó en cuenta la particularidad de la cuestión carcelaria puntarenense y la inexistencia de la planimetría original de los edificios que conformaron el complejo: la cárcel-presidio, la Alcaidía, la casa del alcaide de la prisión, el Juzgado de Letras y la casa del juez letrado. Dicho análisis permitió establecer las diferentes etapas de crecimiento del complejo relacionando todo tipo de fuentes y documentos para proceder a una reconstrucción histórica sobre la evolución arquitectónica del mismo. La suma de documentos analizados se reveló particularmente apropiada considerando tanto las lagunas temporales de las fuentes, como también los documentos inéditos correspondientes a la gestión de la institución carcelaria regional ${ }^{4}$.

En este sentido, se recurrió al material fotográfico disponible en los archivos del Instituto de la Patagonia de la Universidad de Magallanes y del Museo Regional de Magallanes, imágenes que testimonian sutiles cambios en la disposición de elementos de la arquitectura; también se indagó en documentos inéditos del Archivo Regional de Gendarmería de Chile y del Archivo Nacional. Finalmente, se estudió la documentación de prensa de la época, con el objetivo de obtener precisiones acerca del devenir de la institución y de sus instalaciones.

El presente artículo se ha estructurado en cuatro secciones: la primera busca conocer los principales modelos de arquitectura vigentes al momento de iniciarse el proyecto de construcción del complejo penitenciario y judicial de Punta Arenas; una segunda sección presenta el desarrollo de la institucionalidad carcelaria en el país; una tercera sección busca contextualizar el paso de la Colonia Penal existente en Magallanes a una cárcel emplazada en el centro de la ciudad; y una cuarta sección explica la prefiguración, configuración y reconfiguración del Presidio y el Juzgado entre la fecha de inicio de su construcción, en 1898 y la fecha de su clausura, en 2015.

\section{ANTECEDENTES DE LA ARQUITECTURA PENITENCIARIA}

\section{Referentes de la Arquitectura Penitenciaria}

A partir del siglo XVIII, operó en Europa una reflexión profunda sobre el rol y la pertinencia de las instituciones asociadas al encierro, a la que se agregó una visión crítica sobre su estado y la necesidad de reformarlas. Esa reflexión, que trascendió a la prisión e incluyó a los hospitales y a los asilos para pobres y enfermos mentales, tomó 
dimensiones filosóficas, jurídicas y económicas, pero también alcanzó una dimensión espacial, determinada tanto por el debate público como por la profesionalización creciente de arquitectos e ingenieros (Vidler, 1995, p. 11). Hasta ese momento la idea de prisión, como institución destinada a purgar una pena proporcional a un delito y reformarse por medio del encierro, no existía, pero comienza su desarrollo junto a la crítica persistente del estado de aquellos lugares destinados a la detención, tanto por motivos políticos como por prácticas delictuales y criminales.

Así, en Francia, desde 1780, se inició el trabajo de comisiones que evaluaron nuevos proyectos o que visitaron las prisiones existentes y elaboraron informes sobre su localización, sus condiciones materiales y la situación de los prisioneros (Vidler, 1995, p. 230), entre las que impactaron la falta de higiene, el hacinamiento, así como las enfermedades y penurias de los recluidos. Debemos considerar que en el pensamiento enciclopedista y reformador francés trascendieron las ideas del filósofo y criminalista milanés Cesare Beccaria (1738-1794) que abogó por la necesidad de utilizar criterios racionales y científicos durante los procesos judiciales $y$, por el tránsito a una sociedad capaz de prevenir activamente los delitos (Caro, 2011) en vez de reprimirlos a través del castigo, principalmente el suplicio corporal que los códigos penales de fines del siglo XVIII suprimieron (Foucault, 2008, p. 16).

La influencia de Beccaria se dejó sentir también en Inglaterra y Europa, primero a través de la figura y escritos críticos de John Howard (1726-1790) sobre el estado y condiciones de las prisiones y casas de corrección y, posteriormente, a partir de las ideas de Jeremy Bentham (17481842) que permitieron sentar las bases de un nuevo sistema penal, el sistema penitenciario, que pronto se acompañó de una reflexión más fina sobre la arquitectura de las prisiones. En este sentido, caben destacar dos aspectos relevantes de esa reflexión, en primer lugar, la articulación entre el ideario político-filosófico propugnado por reformadores sociales y la construcción de prisiones $y$, en segundo lugar, la especificidad que adquirió la arquitectura penitenciaria (Saldivia \& Caro, 2010; Caro, 2013) y que incidió en aspectos funcionales y espaciales relativos a la organización, distribución y dimensión de recintos o en aspectos urbanos relativos a la localización en función de una clasificación y jerarquización de las prisiones, muchas veces asociadas a los procedimientos judiciales o a la duración de las penas de los condenados.

Junto con lo anterior, la reflexión en torno a la arquitectura de las prisiones se enriqueció por los aportes de Bentham, en la medida que su discurso se acompañó de imágenes que actuaron no sólo como un modelo a implementar, sino también a corregir, a adaptar, a rechazar; o un modelo del cual dudar, tal como lo señalaba en 1829 Louis-Pierre Baltard en su trabajo sobre los sistemas de distribución en la arquitectura de diferentes prisiones, al indicar: protejámonos, si podemos, de generalizar los sistemas Panópticos imitados por los ingleses de la Prisión de Gante y demos garantías a la teoría de la prisión-modelo. [...] Desde hace varios años, hemos optado exclusivamente por el sistema Panóptico, sin poner atención en lo que hay ahí de ilusorio en la vigilancia de un observador ubicado al centro de los radios de los edificios resultado de este sistema de distribución de las prisiones (Baltard, 1829, p. 18). Y es que, el Panóptico de Bentham vulgarizado a partir de $1791^{5}$, concretizó un ideal penitenciario y un modelo arquitectónico simple y de rápida difusión, constituido "en la periferia, [por] una construcción en forma de anillo; en el centro, [por] una torre con anchas ventanas que se abren en la cara interior del anillo. La construcción periférica está dividida en celdas, cada una de las cuales atraviesa todo el ancho de la construcción. Tienen dos ventanas, una hacia el interior, correspondiente a las ventanas de la torre, y otra hacia el exterior, que permite que la luz atraviese la celda de lado a lado. Basta entonces situar un vigilante en la torre central y encerrar en cada celda a un loco, a un enfermo, un condenado, un obrero o un escolar (Foucault, 2008, p. 232). Si bien la representación en planta del Panóptico de Bentham obedece a una figura radial, no quiere decir necesariamente que toda figura radial en relación a la arquitectura penitenciaria fuere panóptica, como fue el caso de la prisión de Gante construida antes de la publicación del texto de Bentham y que se estructuraba a partir 
de una torre octogonal central y cuatro cuerpos destinados a albergar las celdas (Melossi \& Pavarino, 2014, p. 75)

En América Latina, diferentes autores han señalado la importancia del Panóptico como referente teórico (Gutiérrez, 1997; Raffa, 2007) y como modelo de una arquitectura penitenciaria localizada fundamentalmente en las capitales nacionales, tales como la cárcel penitenciaria de Santiago construida entre 1843 y 1847 (Ulloa, 1879; Cisternas, 1998), la penitenciaría central de Lima (Altmann, 1970) construida entre 1856 y $1860^{6}$, el penal García Moreno de Quito construido entre 1868 y $1874^{7}$, la penitenciaria Nacional de Buenos Aires construida entre 1872 y $1876^{8}$, la penitenciaría Central de Cundinamarca en Bogotá construida a partir de $1874^{9}$, la cárcel preventiva, correccional y penitenciaria de Montevideo construida entre 1885 y $1888^{10}$. Por su parte, en Argentina el mismo modelo se utilizó en la cárcel de Mendoza, construida en 1864, y en el presidio de Ushuaia complejo edilicio de forma radial, que respondía a las nuevas tendencias de la ciencia penitenciaria (Cecarelli, 2009, p. 104) de 1902.

En contraste, los modelos denominados en peine $y$ en doble peine que inauguró la prisión de Fresnes, construida entre 1895 y 1898 al sur de París por el arquitecto Henri Poussin, constituyeron referentes más tardíos y menos utilizados como recurso en la arquitectura penitenciaria Latinoamericana (García, 2012). Los elementos que dan forma a este modelo, denominado también de "poste telefónico" o de "espina de pescado", se encuentran constituidos por pabellones de administración, de servicios $y$ principalmente de celdas que se disponen perpendicularmente a un corredor de circulación. Siguiendo a Altmann (1970), la concepción arquitectónica posee dos importantes ventajas: permitir una mejor orientación de los diversos pabellones que caen perpendicularmente al corredor central, favoreciéndose, por tanto, la

6 La Penitenciaría Central de Lima fue demolida a principios de la década de 1960 para situar ahí el Centro Cívico de Lima.

7 Este recinto dejó las funciones de reclusión en diciembre de 2014, pasando a transformarse en museo y lugar de exposiciones.

8 La Penitenciaría Nacional fue demolida a partir de 1961 y ventilación, el asoleamiento, la luminosidad, etc.; y simplificar el movimiento de los reclusos, que ha de efectuarse por dicho corredor central (p. 63).

En Chile durante el siglo XIX la situación carcelaria era tan precaria como en Europa. Siguiendo a León la delincuencia, la falta de recursos, la moralización de los detenidos, la escasez de vigilantes, el desaseo y hacinamiento de las cárceles; son aspectos que no fueron ajenos a las autoridades de los siglos pasados (2008, p. 378). Sumado a esto, las condiciones de la infraestructura carcelaria se arrastraban desde el siglo XVIII, como herencia y continuidad de la época Colonial, en un momento en que la concepción del encierro no sólo no entroncaba con las ideas de castigo, de redención de las culpas y de rehabilitación, sino con la necesidad de contar con lugares de tránsito donde se esperaban condenas mayores, como la ejecución pública, la expropiación de bienes o el destierro (León, 1998, p. 150). Finalmente, los lugares de detención no se encontraban sistematizados ni previstos en una dimensión territorial. Así, la implementación, entre las décadas de 1830 y 1850 , de caravanas sobre las que se montaba una celda, denominadas residios o carros ambulantes, permitiendo el traslado y a su vez el castigo de condenados por medio del encierro y el trabajo forzado, y que funcionaron en Coquimbo, Aconcagua, Santiago, Colchagua, Valparaíso, Talca, Maule y Concepción, permitieron una primera aproximación y experimentación al cumplimiento de penas en un espacio físico móvil, incluso trasladado y expuesto en el espacio urbano (León, 1998, p. 154).

La precariedad de los presidios ambulantes y de los recintos de detención, marcados por la falta de higiene, el hacinamiento, la dificultad de mantenerlos o ampliarlos dada la falta de recursos y por tratarse de recintos incapaces de brindar seguridad buscó ser resuelta en base a una discusión y definición de la implementación de un sistema penitenciario en Chile (León, 1998). Ello redundó

sobre ella se extiende actualmente el Parque Las Heras.

9 La Penitenciaría de Bogotá funcionó hasta 1946, transformándose en sede del Museo Nacional de Colombia a partir de 1948.

10 Funcionó hasta la década de 1980, pasando a ser el centro de diseño industrial y actualmente espacio de arte contemporáneo. 
en medidas singulares, como la construcción de cárceles en diferentes ciudades del país y en una institucionalidad carcelaria de contornos más definidos, que se expresaron paulatinamente en una serie de reglamentos y cuerpos legales dictados desde 1911, cuando se creó el cuerpo de la gendarmería de prisiones, ya que antes de esa fecha, la legislación fue particular, destinada a normas prisiones específicas o a solucionar problemas coyunturales (León, 2003, p.619). Finalmente, se produjeron avances discretos generados por el debate en medios intelectuales referentes a la criminalidad (León, 2014) y por la implementación de registros estadísticos de la población penal a fines del siglo XIX y principios del siglo XX (Palma, 2011, p. 121).

Desde un punto de vista arquitectónico, la construcción de cárceles se vio beneficiada por la Circular de 1846 (León, 2003, p. 602) que estableció tanto la necesidad de contar con celdas individuales en la cárceles a proyectar, como la necesidad de destinar espacios al trabajo en talleres al interior de los recintos, que reemplazaran el trabajo al exterior de ellos. León ha señalado que en un primer momento, entre 1845 y 1853, los fondos presupuestarios se destinaron a la construcción de la Penitenciaría de Santiago y que un segundo momento se inicia durante los años posteriores a la década de 1850, [cuando] la intención principal de las autoridades fue la de reparar viejos presidios, construir y reconstruir las cárceles departamentales y provinciales, $y$, por supuesto, insistir en la idea regenerativa de los criminales a través del trabajo (2003, p. 605), al mismo tiempo ha identificado entre 1847 y 1872 la construcción de 21 recintos carcelarios: seis cárceles públicas, 13 cárceles y dos presidios urbanos, el de Santiago (1865) y el de Lebu (1872) (León, 2003, p. 606). Un tercer momento se da durante la década de 1870 tanto por la racionalización de los presupuestos para la construcción de cárceles como por la nueva legislación tras promulgarse el Código Penal en 1874, que reforzó la privación de libertad como eje de una reforma que hizo aumentar el número de los penados distribuidos en 69 recintos de reclusión (León, 2003, p. 623). El impulso dado por el presidente J. M. Balmaceda a las obras públicas, señala un cuarto y último momento de la estructura carcelaria en Chile durante el siglo XIX, permitiendo aumentar en 18 los recintos carcelarios. Dentro de los cuales se consideraba la ciudad de Punta Arenas.

\section{La institucionalidad}

El desarrollo de la cuestión carcelaria en el país buscó instaurar, establecer y definir una visión con respecto a ella, tanto como un lugar de confinamiento y castigo, como un lugar de reparación de un mal o daño causado, o como un lugar para la reeducación (Foucault, 2008). Estas visiones redundaron en la aparición o reformulación de una institucionalidad, y un marco normativo, que le diera sustento y uniformidad a lo largo del país. Es en este sentido que, tal como plantea León (2003), a partir de 1889 la Dirección General intentó homogenizar a través de circulares, reglamentos y otras disposiciones un panorama tanto o más disímil del que estaba presente en la zona central (p. 750), incluyendo en ello los extremos norte y sur del país.

Es así que, en 1911, se creó el cuerpo de gendarmería de prisiones y se dictó el primer reglamento carcelario nacional. En el mismo se planteó la prevención y rehabilitación de los recluidos, por medio del encierro solitario, el trabajo y la oración (León, 2008, p. 10), asî como la clasificación de los establecimientos, siendo el de Punta Arenas considerado como "presidio" para reos condenados por juzgados, y como "cárcel" para los detenidos y presos preventivamente, según lo establecido por el artículo 312 del Código de Procedimiento Penal (León, 2008, p. 24). También se instauraron las escuelas correccionales, donde ingresaron los menores castigados por los padres o guardadores, según lo establecido en el Art. 233 del Código Civil. Se debe mencionar que el recinto de Punta Arenas no adquirió dicha denominación aún cuando si se registraron casos de ese tipo (Gendarmería de Prisiones, 1911).

El reglamento definió, junto con la clasificación de los establecimientos, su funcionamiento: los roles de los funcionarios, administración y dirección, los castigos e indultos, el ingreso y salida de los reos, las estadísticas del recinto, llegando incluso a definir el tipo de uniformes, la alimentación y la obligatoriedad del trabajo de los reos en talleres. Por otro lado, se 
definió el régimen interno del recinto (Artículos 74-77) en el que se indicó, en función de las características del edificio, la implementación de un régimen celular mixto, con una convivencia en común durante el día y aislamiento en sus celdas por la noche o un régimen celular estricto, principalmente en celdas.

Con todo ello se buscó homogenizar la situación de los distintos establecimientos penales del país y normar la actividad de la institución carcelaria. Se debe mencionar que, si bien su implementación no fue inmediata si produjo una serie de cambios en el funcionamiento de las prisiones en el país, incluido el establecimiento de Punta Arenas, que tuvieron incidencia en el crecimiento y en las modificaciones internas del conjunto edificado.

La definición con respecto a un régimen o modelo carcelario se trató de una problemática global, tal como lo sostiene Ramírez (1998) La reforma carcelaria norteamericana se desarrolló especialmente en torno a la lucha por la prevalencia de dos sistemas rivales de disciplina penal: el sistema Filadelfia y el sistema Auburn (p. 51), ambos basados en el aislamiento individual en una celda. Sin embargo, mientras en el sistema Auburn al prisionero sólo se le aislaba durante la noche, en el sistema Filadelfia, el recluso permanecía recluido durante el día y la noche. En el país la tensión se decantó por la adscripción del sistema Auburn en el año 1847 (León, 2003, p. 423), situación que se modificó nuevamente en 1928 cuando se cambió por el Progresivo de Crofton (León, 2008, p. 11). Este último consideraba cuatro períodos con grados de mayores garantías y libertades por los que el reo pasaba a medida que demostrara su regeneración, por medio de su conducta y los trabajos que realizara. Este finalizaba con la libertad condicional previo cumplimiento de los requisitos que la ley establecía, entre los que se encontraba Haber aprendido un oficio y haber asistido con regularidad y provecho a la escuela del establecimiento y a las conferencias educativas que se dicten, entendiéndose que no reúne este requisito el que no sepa leer y escribir (DL $N^{\circ} 231$, Art. 2). Se normó asimismo los horarios de trabajo, de aprendizaje, de aseo, de descanso, de ejercicios, comidas y conferencias (Art. 34). En cuanto a los castigos estos se concentraron en la privación o restricción de uso de las instalaciones del recinto carcelario. En primer lugar, para los reos rematados, se indicó la privación, hasta por un mes, de visita, correspondencias, recreos, y demás beneficios o recompensas a que tenga derecho, en segundo lugar: Encierro en su celda hasta por un mes, debiendo retirarse la cama durante el día o levantarla en forma que no pueda ser ocupada y Encierro en celda solitaria obscura hasta por quince días, sin más muebles que una tarima (Art. 46). Para los reos procesados o detenidos se establecieron matices como lo fue la privación, hasta por un mes, de comodidades que se haya podido procurar, como ser derecho a ocupar el pensionado, comida preparada afuera, cama especial, uso de luz en la noche, etc. (Art. 47).

En esta fecha se ratificó al establecimiento de Punta Arenas como Presidio (Art. 3) y con una sección de Penitenciaría (Art. 4). Este reglamento establecía que en el caso de ciudades en que existiera Juzgado del Crimen se consideraría además la clasificación de Cárcel. En éste permanecerían los detenidos y presos preventivamente en conformidad a lo establecido en el Art. 312 del Código de Procedimiento Penal y cumplirían sus penas los condenados según el Art. 87 del citado código (Art. 5). Vale la pena mencionar que en Punta Arenas funcionó el Juzgado del Crimen junto con el de Letras, constando su existencia, al menos desde 1904 (Gendarmería de Prisiones, 1904). Del mismo modo se ratificó la separación de mujeres, hombres y menores (Artículos 9 y 10) ya indicada en la norma del año 1911.

El reglamento de 1928 determinó la creación tanto de un Pensionado, es decir, departamentos separados para presos detenidos preventivamente o por primera vez, mediante el pago de una suma diaria (Art. 24), como también la existencia de pulperías en el interior de los establecimientos penales, por cuenta fiscal, para la venta de artículos de alimentación y de vestuario a precio de costo (Art. 69). Situaciones, ambas, que en el establecimiento de la ciudad de Punta Arenas fueron implementadas prácticamente medio siglo después. Con respecto a las visitas, el reglamento indicó que se permitían tanto a penados como a procesados y a detenidos en días 
domingo u otras fechas especiales, estableciendo para ello un lugar para la realización de las visitas, el Locutorio ${ }^{11}$, que contemplaba ventanillas abiertas o con rejilla (Art. 52). En cuanto a la institución, el reglamento estableció secciones administrativas asignadas a empleados civiles en el establecimiento: la sección penal, tesorería y adquisiciones, Contabilidad, Administrativa, médico-criminológica, educacional y almacén (Art. 131). Aparecen también cargos específicos dentro del establecimiento: Jefe del establecimiento (también llamado Director - Alcaide), Empleados Civiles, Oficiales de Guardia, Ayudantes (Sub-Oficial o Dragoneante), Portero (Sub-Oficiales, Dragoneantes) y Jefe de secciones. Ello conllevó, entre otras acciones, la obligatoriedad de llevar registros de prácticamente la totalidad de los aspectos del funcionamiento del establecimiento. Vale la pena notar que el Reglamento, en su Artículo 149, estableció la existencia de una sala de reuniones donde se darán conciertos por los mismos reos, o por las personas o instituciones que autorice el Ministerio, y se exhibirán vistas cinematográficas de carácter moral y educativo. Esto, si bien no se tradujo en una ampliación del establecimiento carcelario o en la habilitación de un recinto específico, se pudo ver expresado en las diversas actividades que se efectuaron en el espacio central del edificio de celdas. Constan, en registros fotográficos, la realización de eventos y celebraciones donde coincidían los funcionarios, los recluidos y las autoridades, así como también quienes animaban los actos.

Posteriormente, el 19 de noviembre de 1965, se promulgó el Reglamento sobre Normas Básicas para la Aplicación de una Política Penitenciaria Nacional (León, 2008, p. 617). Más allá de los asuntos propios de la política carcelaria, este reglamento tuvo la particularidad de presentar en su título cuarto, por primera vez de manera explícita y directa, aspectos en relación con la arquitectura carcelaria: Todo establecimiento penal debe contar con las dependencias necesarias que permitan la clasificación y separación de la población penal e incluso especifica que deben

11 La presencia de un pensionado y locutorio al interior del recinto carcelario consta recién en documentos planimétricos de principios de 1980 (Penitenciaría de existir áreas de recreación y lugares adecuados para el funcionamiento de escuela, talleres o industrias anexas al establecimiento (León, 2008, p. 630), situación que al menos en los casos de la recreación y los talleres es coincidente con lo indicado en la planimetría de 1965 en cuanto a la existencia del patio cubierto juego de reos y talleres de carpintería y zapatería. Asimismo, el reglamento explicitó las condiciones para el personal de los establecimientos penales estableciendo la necesaria autonomía con respecto a las dependencias de los reclusos. Por otro lado, se planteó una orgánica para el estudio, planificación y desarrollo de las modificaciones y construcciones carcelarias. Esta serían dirigidas por el Ministerio de Justicia y para ello dispondría de una sección de planificación que se articularía con el Departamento de Arquitectura del servicio de prisiones para llevar a cabo las propuestas (León, 2008, p. 630). Finalmente, como corolario del Reglamento, se indicó en su Artículo 89 que:

Las reglas enunciadas en los artículos que anteceden deberán adecuarse a las concepciones de la arquitectura carcelaria actual, a las características geográficas de la zona en que se construya el establecimiento, a la utilización racional de los medios y materiales de edificación según la región de que se trate $y$, en general, a las normas de tratamiento penitenciario que contiene este Decreto (León, 2008, p. 631)

Si bien con el espíritu del reglamento se buscaba homogenizar las condiciones a lo largo del país también se comenzaron a reconocer las diferencias de contextos, al menosen sus condiciones territoriales, como también de disponibilidad de recursos, que redundarían precisamente en una diferenciación de las respuestas arquitectónicas de lo carcelario a lo largo del país.

\section{DE LA COLONIA PENAL A UNA CARCEL EN MEDIO URBANO}

La reclusión fue una condición que

Punta Arenas (s.f.) Plano de Agua Potable. Planta. Escala 1:100. Punta Arenas) 
acompañó y determinó gran parte del desarrollo histórico de la Región de Magallanes en sus primeros años de existencia republicana. La condición de Colonia Penal, que ostentó a partir de 1847, fue establecida para evitar eventuales trastornos en la zona central del país por condenados amotinados y como una forma de ejercer soberanía a través de los mismos reos, de quienes debían custodiarlos y de sus familias (León, 1998, p. 166). Experiencia que para Martinovic (2007) es un experimento único en Chile, una empresa prioritaria del gobierno muy distinta a procesos de presidio penal como Juan Fernández, pues en Magallanes el gobierno chileno quiso transformar a los delincuentes en colonos, quiso hacer una ciudad con convictos, no de convictos (p. 28). Esta condición, que dura prácticamente un siglo, marcaría los designios del territorio austral, a pesar de los intentos desde 1878 por revertir dicha condición, situación que no fue conseguida hasta 1941 (Gendarmería de Chile, 2004, p. 4).

En este sentido, la emergencia temprana de la cárcel en la historia de la ciudad, sino consustancial al desarrollo mismo de la urbe, otorgó visibilidad primero a la cuestión del confinamiento, entendido preliminarmente y de manera amplia como la reclusión dentro de límites y, luego, le otorgó visibilidad a su articulación material. La infraestructura dedicada a esos fines, juzgados y penitenciaria, que son ubicados repetidamente, a lo largo de los años, en el centro mismo de la incipiente ciudad de Punta Arenas. El primer establecimiento penitenciario de la ciudad se ubicó frente a la Plaza de Armas, en la esquina de las calles Arauco (actual J. Fagnano) y Maule (actual 21 de Mayo). Inicialmente destinada a Cuartel de Policía, fue levantada en el período del Gobernador Oscar Viel, en el año $1870^{12}$, siendo utilizada con fines penales a partir del año 1892.

No obstante lo anterior, hacia 1890 se registran los primeros intentos administrativos por mejorar las condiciones de la reclusión en el territorio. Dentro del plan de mejoras de obras

12 Se ha dado principio a la demolicion de las miserables ruinas que fueron hasta hace poco dias cárcel pública de Punta Arenas. Según datos que se han publicado, construido el edificio en cuestion en 1870, fué públicas del Presidente José Manuel Balmaceda se estableció la reparación de penitenciarías del país; en el caso de Magallanes se asignó un presupuesto para lo que debía ser el nuevo establecimiento carcelario de la ciudad de Punta Arenas, considerando, entre otros, los costos de obra gruesa así como de alimentación de reos y empleados (León, 2003, p. 740).

En 1896 el Gobernador Mariano Guerrero manifestó las precarias condiciones de las instalaciones de la cárcel en uso (León, 2003, p. 741), solicitando la creación de un nuevo recinto carcelario. Fue así que el proyecto condensó la ya manifestada necesidad local con la política nacional, orientada esta última a la construcción de recintos carcelarios en las principales ciudades del país (León, 2003, p. 627). Se desarrolló de este modo un proyecto de mejora de las instalaciones que, así como el edificio previo, partió de la base de una ubicación privilegiada en la urbe. Esta quedó registrada en plano de la ciudad de 1898, elaborado por Hugo Pietrogrande (1898), en el que se evidencia una reserva destinada a Cárcel y Policía, en el sitio 3 de la manzana 45 y que la prensa describió algunos años después como

Terreno destinado para cárcel i cuartel de Policía, en la misma manzana que deslinda: al Norte, con la calle Santiago con sesenta metros; al Sur, cincuenta i nueve metros setenta centímetros con los sitios números uno i cuatro; al Oriente sesenta i cinco metros, con el Palacio de la Gobernación i terreno reservado para casa del Gobernador; i al Poniente, cincuenta metros con la calle Chiloé. (El Magallanes, 14 de enero 1902)

En el intertanto, ante las inapropiadas condiciones de las instalaciones del edificio dedicado a cárcel, situado a un costado de la Plaza de Armas y, dados los retrasos en la construcción y habilitación del nuevo edificio, se dispuso la habilitación de un recinto carcelario provisorio,

considerado uno de los mas elegantes de su época, hasta el estremo de darse en él un gran baile (1888, apenas ayer?) [...] (El Comercio, 16 de abril 1901, p. 2). 
en una propiedad arrendada para tal fin ${ }^{13}$. Este inmueble, situado en la esquina suroriente de la manzana 30, en el encuentro de calles Santiago (actual W. Seguel) y Talca (actual A. Sanhueza), se encontraba a aproximadamente cien metros del edificio en construcción, fue descrito de la siguiente manera una vez entró en funcionamiento:

El nuevo local es un edificio de ladrillos, con techo de fierro, cuya ubicacion constituye la mejor garantía de salubridad; bastante luz, buena ventilacion i terreno seco. Los departamentos destinados a los reos, tanto de cárcel como de presidio, son cuatro, $i$ mide el mas grande de $6 \times 5.50 \mathrm{~m}$; otro mas chico $5.50 \times 4.50 \mathrm{~m}$, i cada uno de los otros dos $3.50 \times 3.50 \mathrm{~m}$, lo que constituye una area de 72 metros 25 centimetros cuadrados (El Comercio, 26 de julio 1902, p. 2).

Por otro lado, desde un punto de vista administrativo, el año 1893, el Gobernador Manuel Señoret solicitó la creación de un juzgado letrado para la ciudad (Martinic, 2006, p. 773), necesidad que fue justificada con el aumento de los sucesos delictivos ocurridos en dicha época en el territorio ${ }^{14}$. En este sentido es recién hacia fines del mismo año, exactamente el 23 de Diciembre de 1893, que se crea el Juzgado de Letras (Baeriswyl, 2001,

13 Por el señor alcaide fuimos invitados ayer a visitar el local para la cárcel provisoria que se ha arreglado con este fin en un edificio de material ubicado en la calle de Santiago, esquina Talca. [...] Se piensa tener terminadas estas obras para fines de la presente semana, de modo que en la entrante se trasladarán todos, reos i guardianes, al nuevo edificio, abandonando el que ahora ocupan $i$ que tan poca seguridad ofrece para la cantidad de camas de 40 reos que allí se encuentran detenidos. De regreso visitamos el edificio en construccion detrás de la Gobernación Civil notando con satisfacción que también aqui se trabaja activamente para terminar esa obra que se construye con la solidez que requiere un establecimiento penal de tal naturaleza (El Comercio, 20 de marzo 1901, p.3).

14 Esta situación quedó registrada en la correspondencia de Noviembre de 1893, entre la Gobernación del territorio y el Ministerio de Relaciones Exteriores y Colonización: Alentada la criminalidad por las dificultades insalvables originadas por la impericia i falta de autoridad de los jueces actuales, va adquiriendo a cada momento más audacia i ensanchando su campo p. 94) y en 1897 , el cargo de Alcaide y Guardia de Cárcel. Ello evidenció que el requerimiento de infraestructura no sólo fue un problema del recinto carcelario, sino también de los Juzgados recientemente creados. Esto generó dificultades de operación, tanto para sus funcionarios como para el público que acudía ${ }^{15}$, lo que hizo patente la prensa al remarcar la necesidad de visibilizar la presencia y las labores del juzgado. Esto conllevó la inclusión del juzgado como parte de las instituciones que debían resolver su requerimiento de infraestructura en el predio destinado para fines carcelarios.

Los edificios del conjunto, constituido por Cárcel-Presidio, Alcaidía, Juzgado y Casa del Juez, fueron proyectados para un terreno donde además se encontraban la catedral de la ciudad (1892), un colegio salesiano (1892) y la Gobernación Provincial (1898). Este sitio constó finalmente de $37,92 \mathrm{~m}$ de frente por calle Santiago, de 50,12 m de frente por calle Chiloé, de 44,60 $\mathrm{m}$ de fondo paralelo a calle Santiago y 50,05 m de fondo paralelo a calle Chiloé.

\section{PREFIGURACIÓN, CONFIGURACIÓN Y RECONFIGURACIÓN DE UN ESPACIO CARCELARIO}

La aparición y evolución de la institución carcelaria obedeció, tal como se ha expuesto, a

de operaciones i los particulares se sienten fatalmente inclinados en sus diferencias entre ellos a hacerse justicia por sí mismos o recurrir a represalias que significan nuevos delitos. [...] En el estado floreciente de la Colonia esos malos hábitos que empiezan a diseñarse i que son exclusivamente originados por la lenta $i$ deficiente administración judicial, llegarían, una vez en completo desarrollo, a constituir un verdadero peligro para la tranquilidad pública [...] (Martinic, 2006, p. 773).

15 El juzgado de la subdelegacion primera, funciona actualmente en una sala del edificio del correo. No se ocultará la ventaja que hai en trasladar este juzgado a otra oficina que no sea la nombrada, o, en caso de ser posible, a una seccion independiente. La oportunidad se presenta: colóquese el juez de la primera subdelegacion en las dos salas vacantes del ex edificio de la cárcel. Se nos dice que no hai absolutamente comodidad para el juzgado en las salas del correo, i ademas para el público es un inconveniente, pues puede decirse que actualmente el juzgado de subdelegacion funciona de incógnito (El Comercio, 3 de abril 1901, p. 2) 
la reflexión en torno al rol de la reclusión, como castigo, como posibilidad de reformar o como medio de relegar. Dicha evolución es también producto de los modos bajo los que se materializaron dichas visiones. Sin embargo, estos manifiestos en contadas ocasiones fueron concretados sin la consideración de las circunstancias y restricciones que alteraron las visiones o referentes, institucionales y físicos, situación de la que el conjunto carcelario de Punta Arenas no fue ajeno.

A partir de las fuentes documentales se logró establecer etapas en la evolución de los edificios, en torno a fechas o períodos, que permitió entender en mayor medida el desenvolvimiento y la relación, no siempre directa, entre la institucionalidad y su configuración física. Se propusieron así siete momentos, desde los inicios de su construcción hasta su cierre definitivo, estos son: etapa inicial 1898-1900, etapa de 1903, etapa de 1910, etapa de 1928, década de 1960, décadas de 1980-1990 y etapa de cierre 2005-2015.

\section{Etapa Inicial 1898-1900: construcción sección} celdas de la cárcel-presidio de Punta Arenas

Las obras se iniciaron el 14 de febrero de 1898, con la aceptación de la propuesta de presupuesto del Sr. Enrique Droguett, para la construcción de los cimientos del Cuartel de Policía y Cárcel de la ciudad de Punta Arenas. Es el mismo contratista quien, prácticamente un mes después del inicio de las labores, detuvo las obras por no habérsele cancelado lo acordado. Esto, que quedó extensamente registrado en la correspondencia entre la Gobernación Regional y el Ministerio de Industria y Obras Públicas (Ministerio de Industria y Obras Públicas, 1898), redundó en un retraso de más de nueve meses ya que la continuación de las obras sólo se pudo efectuar a partir del mes de diciembre de 1898, siendo concluidas las fundaciones de ambos edificios el 8 de febrero de 1899 (Ministerio de Industria y Obras Públicas, 1899). Este hecho revistió cierta importancia ya que se trató del momento en el cual se separó en términos prácticos la construcción de la Cárcel de la construcción del Cuartel de Policía, esto aún cuando en la prensa de la época se continuó mencionando el cuartel como parte integrante del proyecto.
Resueltos los problemas que motivaron la detención de la construcción de los cimientos, las siguientes obras se habrían reiniciado con posterioridad al mes de marzo de 1899 (El Magallanes, 23 de marzo 1899), esta vez exclusivamente en la sección celdas. Si bien el proyecto inicial consideró la construcción del complejo en base a la edificación del Cuartel Policial, la Alcaidía y la Cárcel, al momento del reinicio de las obras tanto la construcción del Cuartel como de la Alcaidía debieron detenerse en favor del cuerpo de la sección celdas, alcanzándose a construir de las dos primeras sólo sus fundaciones. Fue así como se desarrolló exclusivamente la construcción del cuerpo de celdas, erigiéndose en el interior del predio un volumen regular, de poco más de veinticinco metros de largo por poco menos de veintidós metros de ancho, a quince y veintiún metros de calles Chiloé y Santiago, respectivamente (Fig. 2).

El proyecto inicialmente elaborado por la Dirección de Obras Públicas de Santiago (Navarro, 1908, p.29) consideró un cuerpo de celdas de sólo un nivel, situación que hubo de ser rectificada por el arquitecto del Ministerio de Industria y Obras Públicas radicado en la ciudad, el Sr. Antonio Allende, con el objetivo de duplicar la capacidad del recinto dada la creciente demanda por la reclusión de penados (Ministerio de Industria y Obras Públicas, 1898). Fue así como finalmente este cuerpo contempló dos pisos destinados a un total de cincuenta y cuatro celdas (Martinic, 2013, p. 7) y un tercero, con cuatro grandes departamentos (El Magallanes, 17 de diciembre de 1899) situados en ambos frontones del volumen, los que quedarían sin un uso asignado. Este volumen consideraba, en ambos niveles, las celdas en el perímetro, cada una con una pequeña ventana con barrotes hacia el exterior y la puerta, con ventanillas vigías, hacia un patio central en el primer nivel, y hacia un pasillo perimetral abalconado en el segundo nivel. Las celdas, de aproximadamente un metro y ochenta y cinco centímetros por tres metros de profundidad, estuvieron originalmente dedicadas a un solo recluido. El acceso se situó en el eje de la cara orientada hacia calle Santiago, esta simetría axial se vio reforzada en su interior por una escalera de madera que conectaba ambas plantas. Desde la segunda planta se desarrollaron, en ambos frontones, escaleras que conducían a los recintos de tercer nivel. 


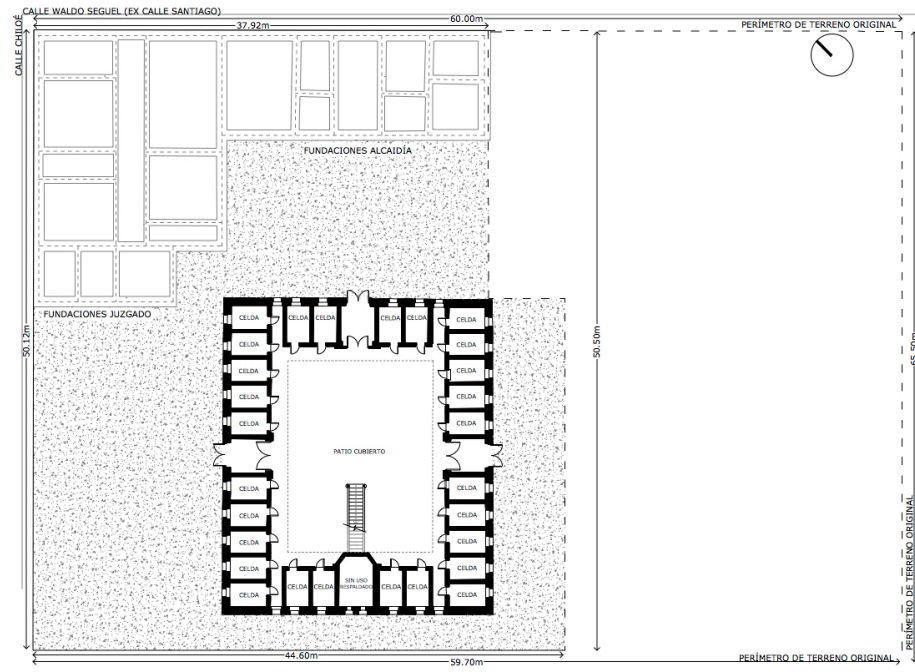

ETAPA INICIAL 1898

PLANTA ARQUITECTURA PRIMER NIVEL

SECCIÓN CELDAS CÁRCEL-PRESIDIO FUNDACIONES ALCAIDÍA Y JUZGADO

Fuente: Interpretación de los autores, diarios El Comercio y EI Magallanes (diversas fechas), Documentos Archivo Dirección Regional de Gendarmería de Chile (Región de Magallanes y Antártica Chilena), antecedentes del Concurso Nacional de Arquitectura. Anteproyecto Biblioteca Regional Anteproyecto Biblioteca Regional y Archivo Regional de Magallanes (Direccion de Bubliotecas, Archivos $y$ Museos, 2014), Archivo Fotográfico Histórico Patrimonial Instituto de la Patagonia-

Magallanes.

$\begin{array}{llllll}0 & 5 & 10 & 15 & 20 & 25\end{array}$

ETAPA INICIAL 1898

PLANTA ARQUITECTURA SEGUNDO NIVEL

SECCIÓN CELDAS CÁRCEL-PRESIDIO

Fuente: Interpretación de los autores, diarios EI Comercio y El Magallanes (diversas fechas), Documentos Archivo Dirección Regional de Gendarmería de Chile (Región de Magallanes y Antártica Chilena), antecedentes del Concurso Nacional de Arquitectura. Anteproyecto Biblioteca Regional y Archivo Regional de Magallanes (Dirección de Bibliotecas, Archivos y (Direccion de Bibliotecas, Archivos $y$ Museos, 2014), Archivo Fotográfico Histórico Patrimonial Instituto de la
Patagonia- Universidad de Magallanes.

$\begin{array}{lllll}0 \quad 5 \quad 10 & 15 & 20 & 25\end{array}$

ETAPA INICIAL 1898 PLANTA ARQUITECTURA TERCER NIVEL

SECCIÓN CELDAS CÁRCEL-PRESIDIO

Fuente: Interpretación de los autores, diarios El Comercio y E Magallanes (diversas fechas), Documentos Archivo Dirección Regional de Gendarmería de Chile (Región de Magallanes y Antártica Chilena), antecedentes del Concurso Nacional de Arquitectura. Nacional de Arquitectura. Anteproyecto Biblioteca Regional $y$ Archivo Regional de Magallanes (Dirección de Blbliotecas, Archivos $y$ Museos, 2014), Archivo Fotográfico Histórico Patrimonial Instituto de la PatagoniaMagallanes. 
En términos materiales el edificio de albañilería, cerrado por una cubierta de fierro galvanizado a dos aguas con una claraboya central, se estructuró en base a bóvedas de cañón rebajado correspondientes a cada celda individual. El volumen se caracterizó por su hermetismo y por las pequeñas aberturas de ventilación e iluminación de las celdas, así como por la claraboya en la cumbrera de la cubierta que se desarrolló prácticamente de extremo a extremo.

Cabe mencionar que las demoras en la ejecución de la construcción también repercutieron en modificaciones en términos del profesional a cargo de las obras. Ésta fue, inicialmente, dirigida por el arquitecto Antonio Allende, Director de Obras Públicas del territorio, dependiente del Ministerio de Industria y Obras Públicas, quien desarrolló las primeras modificaciones del proyecto, entre las que se contó la mencionada ampliación del cuerpo de celdas, su participación en la construcción consta hasta el día 24 de noviembre de 1898 cuando se le solicitó informar respecto al cumplimiento de las obras en relación a lo indicado en las especificaciones técnicas (Ministerio de Industria y Obras Públicas, 1898). A partir de inicios de 1900 consta la participación del arquitecto de la Gobernación Antonio Beaulier (El Magallanes, 11 de Febrero 1900) quien, según detalla la prensa, también habría modificado el proyecto.

\section{Etapa de 1903: Construcción: Alcaidia, Galería, Baños y Cocina y almacén. Configuración del Camino de Ronda y Patio de Alcaidía.}

Habiéndose concluido, en fecha indeterminada previa a febrero de $1902^{16}$, las obras de la sección de celdas ${ }^{17}$, se efectuaron los llamados para la consecución de las labores donde

Fig. 2. Ciudad de Punta Arenas, fundaciones de Alcaidía y cuerpo central de celdas.

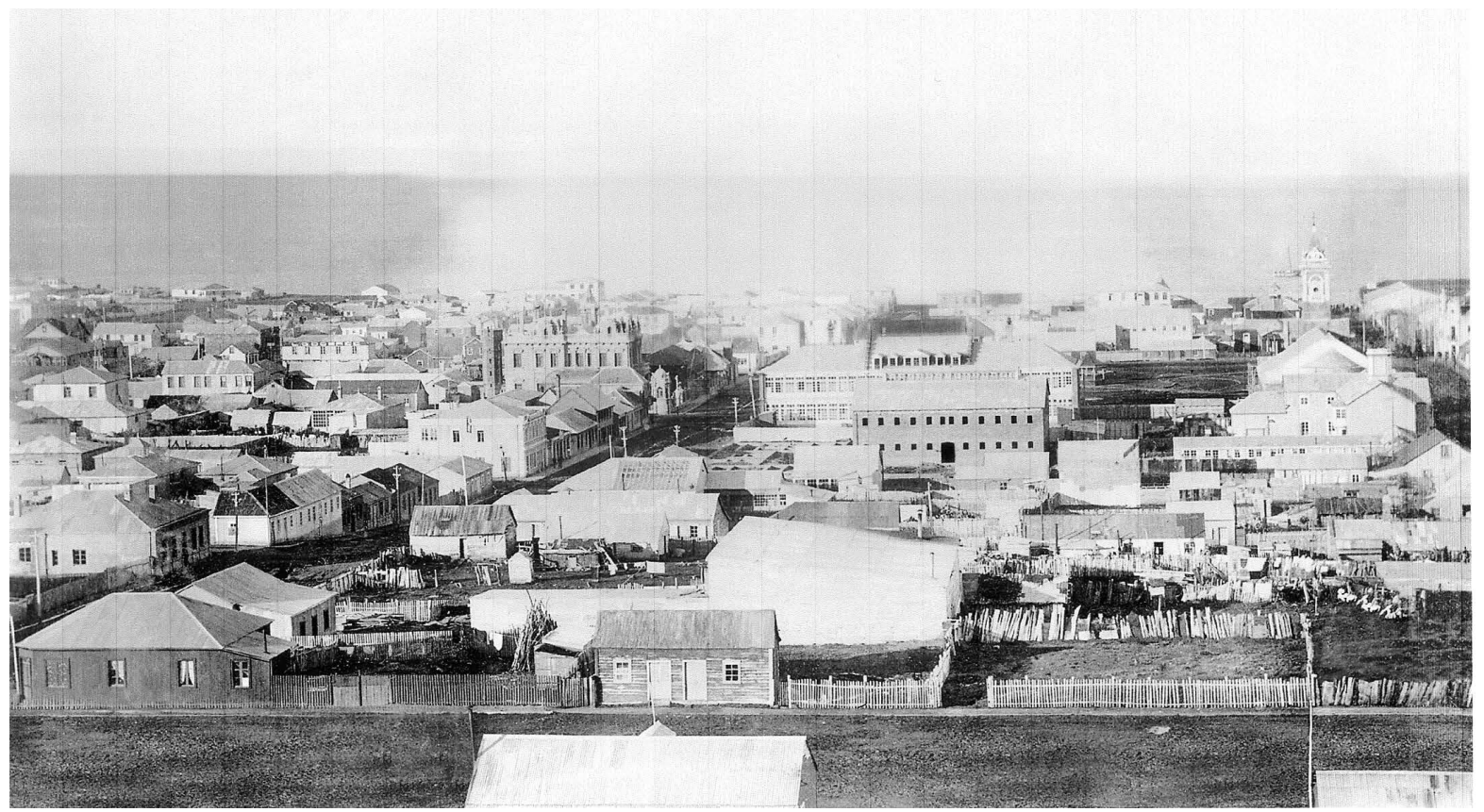

Fuente: Colección CEHA Archivo Fotográfico Histórico Armando Braun Menéndez UMAG IDP.

16 En el mes de febrero consta su utilización como oficina para las matrículas de la Escuela Superior de Niños (El Comercio, 22 de febrero 1902, p. 2). Posteriormente se usó como cuartel de la Compañía de Ingenieros Militares (El Comercio, 18 de marzo 1902, p. 2) y, en el mes de abril, como cuartel de los 104 soldados de la Compañía Arauco (El Comercio, 9 de abril 1902, p. 2).
17 La prensa de la época constataba así el estado de la obra: La sección construida de la cárcel que ocupa la parte central del sitio; los anexos en proyecto consistentes en calabozo común; calabozos para incomunicados; talleres, cocina escusados, cuerpo de guardia i oficina i casa habitacion para el alcaide, no se han comenzado aun (El Comercio, 1 de agosto 1902, p. 2) 
se recibieron las propuestas para la construcción del edificio de Alcaidía, la galería de comunicación entre este y las celdas, la cocina y almacén, el camino de ronda, un taller, calabozos comunes y baños (El Comercio, 1 de octubre 1903). En estas el edificio de Alcaidía constaba del cuerpo de guardia, oficinas y la casa habitación para el Alcaide (El Comercio, 1 de agosto 1902, p. 2).

Estas obras, específicamente la construcción de la Alcaidía, le entregaron la primera cara propiamente urbana al complejo. El volumen, de muros de albañilería y entrepisos de madera, se ordenó en base a la simetría del cuerpo de celdas, la que, articulada por la galería de comunicación, se constituyó en el acceso y conexión entre ambos volúmenes, conformando el recorrido de ingreso al interior del recinto carcelario que se mantendría hasta su cierre. Esta simetría también se expresó en su imagen hacia la calle donde, si bien se trató de una fachada liberada de ornamentos, se reforzó el acceso con un frontón entrecortado sobre la cornisa que, a partir de fecha indeterminada, acogió en altorrelieve el nombre y uso del edificio. Dado que el edificio de Alcaidía consideró además en su segundo nivel, con un acceso independiente, la vivienda del Alcaide, se rompió la composición equilibrada de la fachada con un ingreso lateral menor que, junto con el principal al recinto, fueron los elementos que caracterizaron la composición del segmento construido hasta ese instante. Asimismo destacaron en la fachada las proporciones y la secuencia de composición del segundo nivel, en este el arquitrabe se situó directamente sobre las aberturas, sin dejar el espacio donde generalmente se ubicaban los frontones de las ventanas. Esta omisión, ya fuere por restricciones presupuestarias o por decisiones de proyecto, terminó de otorgarle al edificio una cierta rigurosidad y sobriedad que se verá intensificada una vez erigidos los edificios a sus costados.

Interiormente, el inicio de los trabajos de construcción, a partir de fines de 1904, de la muralla de cal y ladrillos marcaron la completa separación del recinto de la cárcel del Cuartel de Policía (El Magallanes, 15 de diciembre 1904). Esto produjo la definición del Camino de Ronda, circulación perimetral a las celdas que permitía la vigilancia del contorno del volumen. Por otro lado, también en el interior del predio, se construyeron dos cuerpos separados para alojar en uno de ellos los baños y en el otro la cocina y almacén. El primero adosado al muro divisorio con el Cuartel de Policía, y los segundos situados en la esquina surponiente del predio, en lo que se denominaban patios oriente y poniente de la cárcel (El Magallanes, 17 de diciembre 1899).

La construcción del edificio de la Alcaidía, con su segundo nivel de mayores dimensiones y proyectado sobre el primer nivel, configuró un corredor interior que, junto con la galería de comunicación, definieron el espacio, denominado Patio de la Alcaidía, situado entre esta y el cuerpo de celdas. Finalmente, en cuanto a los calabozos

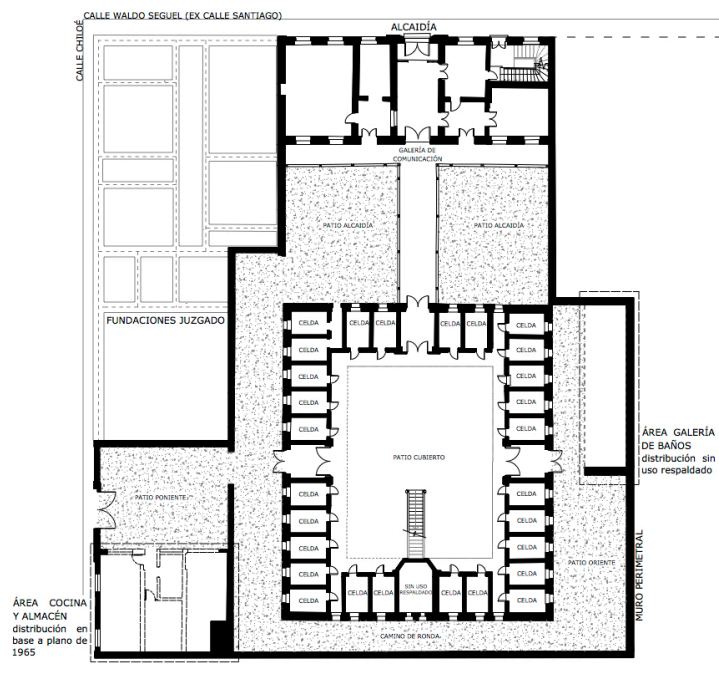

ETAPA DE 1903

PLANTA ARQUITECTURA PRIMER NIVEL

ALCAIDÍA, GALERÍA DE BAÑos, COCINA Y ALMACÉN, MURALLA PERIMETRAL

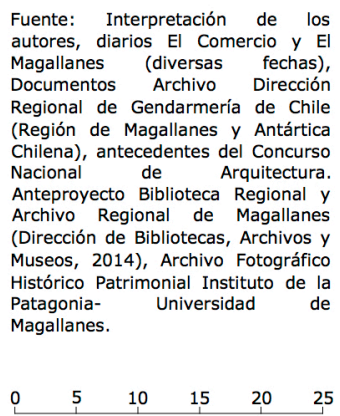

$\begin{array}{lllll}1 & 10 & 15 & 20 & 25\end{array}$

*TRAZOS SEGMENTADOS CORRESPONDEN A ELEMENTOS DATA EN LOS CUALES, DADO EL NIVEL DE INTERVENCIÓN ACTUAL, NOES POSIBLE ACTUAL, NO ES POSIBLE ABERTURAS, ASÍ COMO SU DISTRIBUCIÓN INTERIOR. ' 

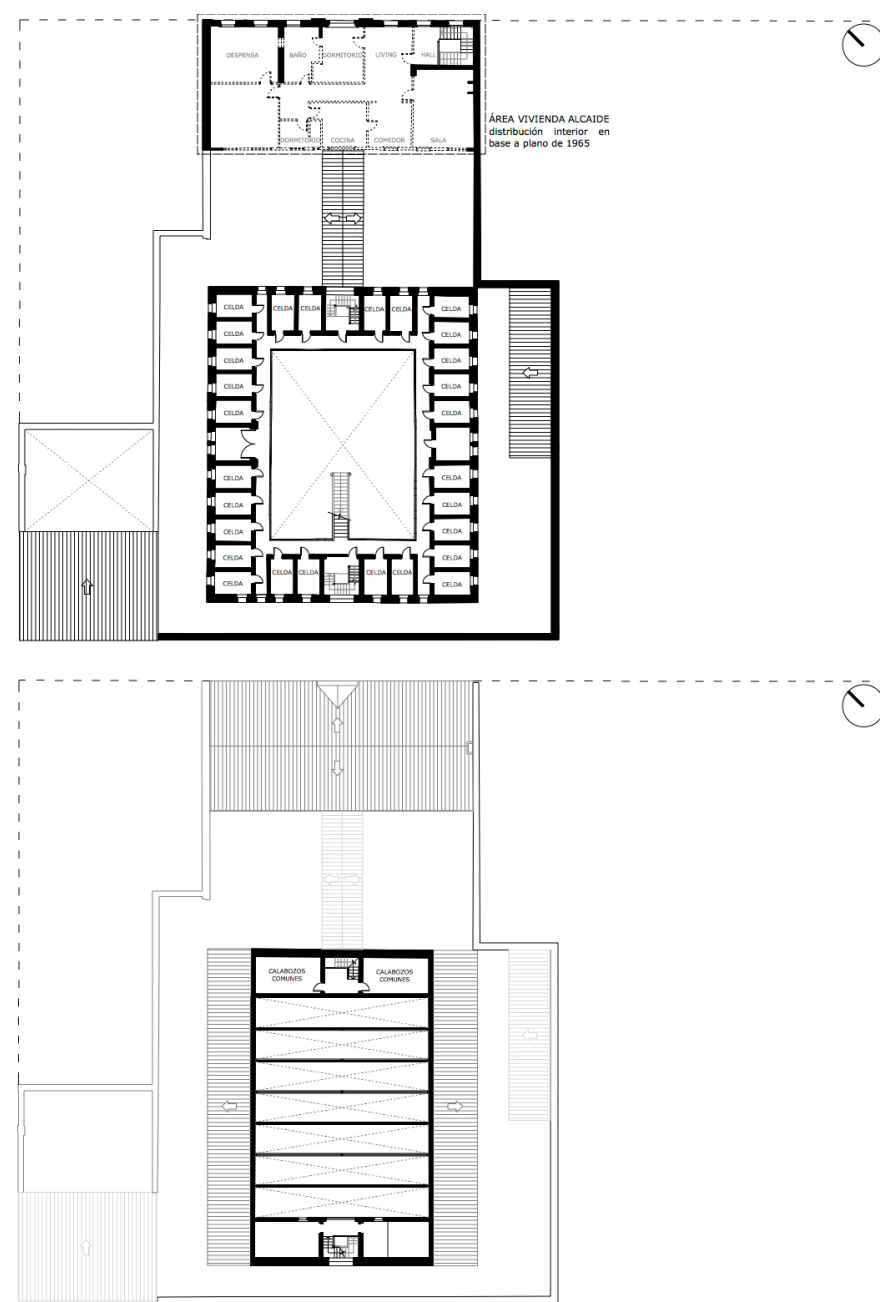

comunes, estos, aparentemente, se habrían habilitado en los recintos disponibles del tercer nivel.

Cabe mencionar que la sección de celdas no consideró en sus inicios un sistema de calefacción que permitiera hacer frente a las bajas temperaturas locales. Esto fue implementado posteriormente, siendo la circunstancia que retrasó la ocupación efectiva del edificio por parte de los recluidos. El calorífero, solicitado a una fábrica parisina (El Comercio, 25 de junio 1905, p. 2), habría considerado, según la prensa de la época, la construcción de una pieza subterránea para la instalación de la caldera (El Comercio, 19 de enero 1906, p.3), situación que habría sido desechada a cambio de la utilización, para tales efectos, de dos celdas de la esquina norponiente del cuerpo de celdas. Este sistema de calefacción

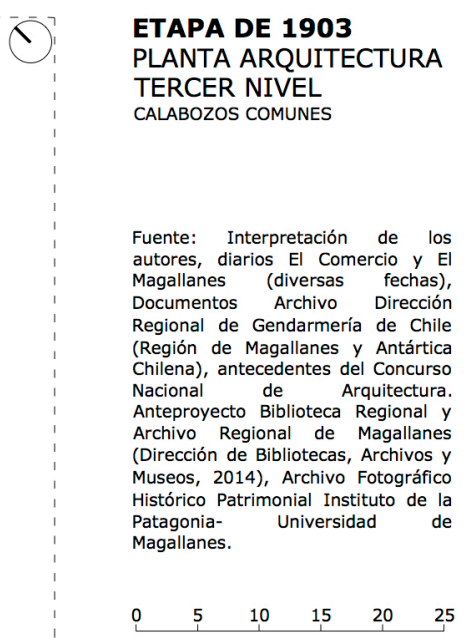

ETAPA DE 1903

PLANTA ARQUITECTURA

SEGUNDO NIVEL

VIVIENDA ALCAIDE

Fuente: Interpretación de los autores, diarios El Comercio y El Magallanes (diversas fechas), Documentos Archivo Dirección Regional de Gendarmería de Chile (Región de Magallanes y Antártica Chilena), antecedentes del Concurso Nacional de Arquitectura. Anteproyecto Biblioteca Regional y Archivo Regional de Magallanes (Dirección de Bibliotecas, Archivos y Museos, 2014), Archivo Fotográfico Histórico Patrimonial Instituto de la

Patagonia- Universidad de Magallanes.

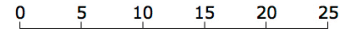

ETAPA DE 1903

PLANTA ARQUITECTURA TERCER NIVEL

Fuente: Interpretación de los autores, diarios El Comercio y EI Magallanes (diversas fechas), Documentos Archivo Dirección Regional de Gendarmeria de Chile Ce Magallanes y Antártica (antecedentes del Concurso Anteproyecto Biblioteca Regional y Archivo Regional de Magallanes Airección de Bibliotecas, Archivos y Museos, 2014), Archivo Fotográfico Histórico Patrimonial Instituto de la Patagonia-

$\begin{array}{llllll}0 & 5 & 10 & 15 & 20 & 25\end{array}$

entró en funcionamiento a mediados de 1907 (El Comercio, 5 de Junio 1907, p. 3), determinando el traslado de los recluidos al recinto carcelario el día 29 de junio (El Magallanes, 26 de junio 1907). En cuanto al desarrollo de las obras hacia 1906 constaba la detención de las faenas de construcción del edificio del Juzgado. (El Magallanes, 28 de abril 1906).

Etapa de 1910: Construcción Juzgado de Letras y Casa del Juez. Ampliación y remodelación de la Sección Celdas: por construcción de los calabozos de Sección Mujeres y sus baños.

La detención inicial en el desarrollo de las obras produjo un giro en la programación de las mismas, así como un cambio en la consideración 
de los edificios que llegaron a formar parte del complejo. A partir del segundo semestre del año 1902 la prensa hizo eco de la inclusión de otras instalaciones en cuanto al proyecto ...Esta construccion comprenderá ademas, Juzgado $i$ casa habitacion para el Juez; Notaria; Rejistro Civil i oficinas de Injenieros de Colonizacion (El Comercio, 1 de agosto 1902, p. 2). La omisión del Cuartel de Policía, que en un futuro se erigiría de manera independiente a la cárcel, dio paso a la consideración del Juzgado y casa habitación del Juez como parte del proyecto carcelario. El detalle de recintos de este último edificio se vio revelado por la prensa local prácticamente tres años después, en 1905 el diario El Magallanes indicó que La planta baja del edificio del Juzgado tendrá salas de espera, sala de abogados, cómodas oficinas para Secretaria i un hermoso salon para despacho del Juez. En los altos tendrá el Juez su domicilio particular (El Magallanes, 28 de Julio 1905). ${ }^{18}$

Es así que, recién hacia el año 1910, se iniciaron los trabajos menores de construcción para la conclusión del edificio del Juzgado (El Magallanes, 19 de mayo 1910). Éste, situado en la esquina del predio que daba a calles Chiloé y Santiago, también consideró dos niveles, en el primero se ubicaron las oficinas de Juzgado propiamente tal y en el segundo nivel se localizó la vivienda del Juez. Con usos independientes en cuanto a sus niveles, presentó accesos en los ejes de simetría por ambas calles, para el juzgado por calle Santiago y para la vivienda del Juez por calle Chiloé. Esta última consideró, además, un patio de servicio por calle Chiloé colindante con el patio de acceso al recinto carcelario. Funcionalmente, el edificio del Juzgado fue concebido independiente del recinto carcelario, aún cuando consideró una vía de comunicación interna entre el patio de la Alcaidía y el Juzgado ${ }^{19}$.

En términos materiales se trató de un

18 Si bien en la nota se incluye una indicación al cuartel de Policía esta se debe a que inicialmente se consideraron como un complejo unitario. Las circunstancias, el desarrollo de las obras y lo efectivamente construido evidenciaron su autonomía.

19 La puerta interior consta además en correspondencia de Gendarmería de Prisiones (Gendarmería de Prisiones, 1928 , p. 3). Esta se habría construido para el ingreso de internos al juzgado como parte del proceso judicial.

20 Al respecto se menciona en la prensa de la época que se volumen de albañilería de ladrillo que, en parte, estructuró su entrepiso en base a bóvedas catalanas dispuestas en sentido transversal a calle Chiloé ${ }^{20}$, el resto del entrepiso se estructuró en base a vigas, viguetas y piso de madera. Consideró también una estructura de cubierta en base a cerchas de madera que soportaron una cubierta a cuatro aguas. Si bien, volumétrica, estructural y funcionalmente, se trató de un edificio autónomo, su fachada continuó, en su primer nivel, las líneas y proporciones del edificio ya construido de la Alcaidía. No ocurrió así en el segundo nivel donde el edificio del Juzgado aumentó su altura de recinto interior y en el exterior agregó frontones sobre las aberturas, rebajados sobre las ventanas y circulares sobre la puerta del balcón, lo que tuvo como consecuencia que el edificio del Juzgado fuera, en altura, levemente mayor al de la Alcaidía. Esta situación se vería reforzada poco tiempo después al quedar el edificio de la Alcaidía como eje de simetría, al construirse la Prefectura de Carabineros en su costado opuesto (fecha no establecida, entre 1910 y 1918).

La simetría de la fachada del edificio del Juzgado por calle Santiago se acentuó con la instalación en su eje, sobre el acceso, de un balcón de fierro forjado $y$, sobre este último, de la construcción de un frontón rebajado donde se inscribió en altorrelieve el destino del edificio: JUZGADO de LETRAS. En cuanto a su fachada por calle Chiloé, esta mantuvo las proporciones y las relaciones de llenos y vacíos de la fachada por calle Santiago, lo que implicó la necesidad de simular vanos en los extremos de la fachada de primer nivel, en esos casos rehundiendo la albañilería.

Por otro lado, en este período se construyó, en el interior del predio, específicamente en el patio oriental de la Alcaidía, lo que sería la sección mujeres del recinto carcelario. Esta consideró tres calabozos, ubicados en el cuerpo

consulta la construcción de dos bóvedas contra incendio para guardar el archivo $i$ documentos mas importantes de esas oficinas, los que en caso de siniestro como el que casi hemos tenido la desgracia de lamentar anoche, serian consumidos por el fuego, ocasionándose con ello pérdidas irreparables. El casi siniestro de anoche es una útil advertencia que debe aprovecharse, i el modo de hacerlo es proceder cuanto antes a la construcción de la parte del edificio que hemos indicado, con las bóvedas contra incendio respectiva (El Comercio, 28 de mayo 1903, p. 3) 


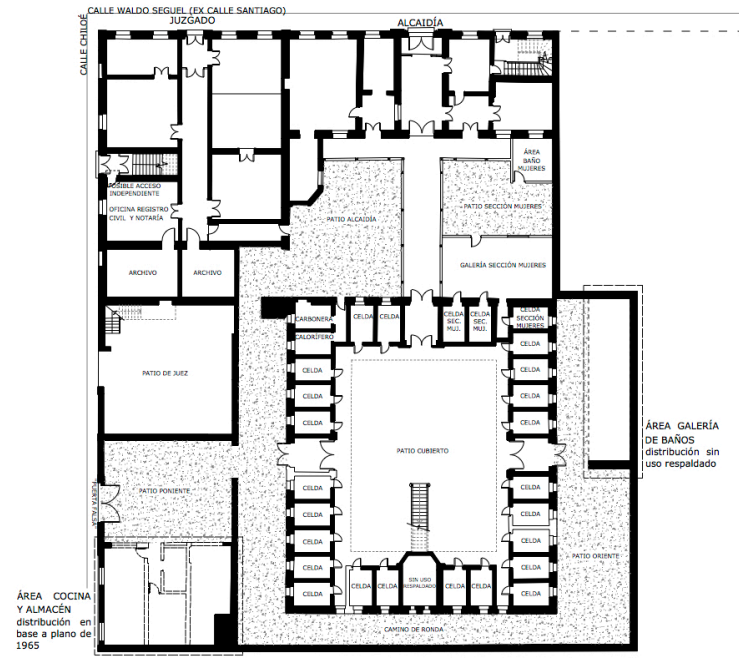

ETAPA DE 1910

PLANTA ARQUITECTURA

PRIMER NIVEL

JUZGADO DE LETRAS

NOTARÍA, REGISTRO CIVIL Y

OFICINAS INGENIEROS DE COLONIZACIÓN SECCIÓN MUJERES

Fuente:Interpretación de los autores, diarios El Comercio y El Magallanes (diversas fechas), Documentos Archivo Dirección Regional de Gendarmería de Chile (Región de Magallanes y Antártica Chilena), antecedentes del Concurso Nacional de Arquitectura. Anteproyecto Biblioteca Regional y Archivo Regional de Magallanes (Dirección de Regional de Magallanes (Dirección de Bibliotecas, Archivos y Museos, 2014), Archivo Fotográfico Histórico Patrimonial Instituto de la PatagoniaUniversidad de Magallanes.

\begin{tabular}{llllll}
$0 \quad 5$ & 10 & 15 & 20 & 25 \\
\hline
\end{tabular}

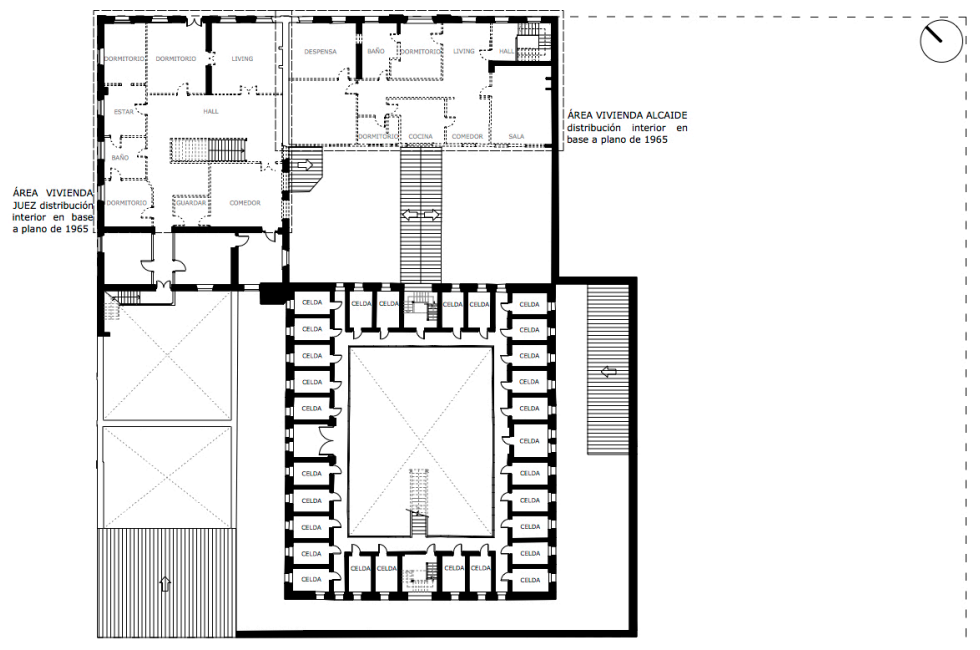

ETAPA DE 1910

PLANTA ARQUITECTURA

SEGUNDO NIVEL

VIVIENDA DEL JUEZ

Fuente:Interpretación de los autores, diarios El Comercio y El Magallanes (diversas fechas), Documentos (diversas fechas), Documentos Gendarmería de Chile (Región de Gendarmería de Chile (Región de Magallanes y Antártica Chilena), de Arquitectura. Anteproyecto Biblioteca Regional y Archivo Regional de Magallanes (Dirección de Bibliotecas, Archivos y Museos, 2014), Archivo Fotográfico Histórico Patrimonial Instituto de la Patogorico Universidad de Magallanes.

$\begin{array}{llllll}0 & 5 & 10 & 15 & 20 & 25\end{array}$

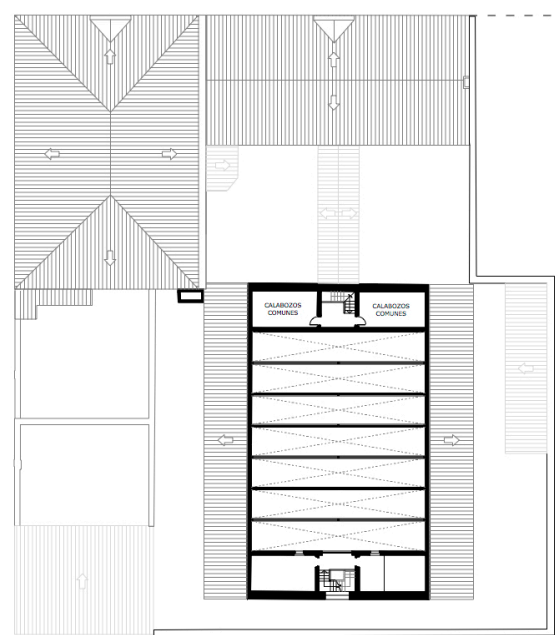

ETAPA DE 1910

PLANTA ARQUITECTURA TERCER NIVEL

Fuente:Interpretación de los autores, diarios El Comercio y EI Magallanes (diversas fechas), Documentos Archivo Dirección Regional de Gendarmería de Chile (Región de Magallanes y Antártica Chilena), antecedentes del Concurso Nacional de Arquitectura. Anteproyecto Biblioteca Regional y Archivo Regional de Magallanes (Dirección de Regional de Magallanes (Dirección de Bibliotecas, Archivos y Museos, 2014), Archivo Fotográfico Histórico Patrimonial Instituto de la PatagoniaUniversidad de Magallanes.

$\begin{array}{llllll}0 & 5 & 10 & 15 & 20 & 25\end{array}$ 
principal del edificio, i que tienen salida a una gran galeria [sic], la que servirá a las detenidas de patio i comedor. Esa galeria [sic] no tiene comunicacion [sic] alguna con el patio principal de los reos hombres. En la citada galeria [sic] se instalarán armarios i mesas para las penadas. Hai [sic] allí, además, un lavatorio con agua corriente. Separado por un pequeño pedazo de patio, se sigue despues [sic] un departamento donde está instalado el $<<$ water closet $>>$ i el baño (El Magallanes, 19 de julio 1910).

Es en este período, en torno al año 1910, que se produjo la completa ocupación del predio. Si bien aún permanecían algunos sectores disponibles como exteriores, estos ya poseían un uso determinado, ya fueran patios, como es el caso del perteneciente a la casa del Juez, los correspondientes a la Alcaidía y el patio de trabajos, o bien se tratara de circulaciones exteriores para el control, como es el caso del Camino de Ronda. Asimismo, con la construcción del edificio del Juzgado, se completó también la cara urbana del conjunto en cuanto a sus dos fachadas, las de calles Santiago y Chiloé, imagen que permanecería prácticamente inalterada hasta el cierre de los recintos el año 2015.

Etapa de 1928: Ampliación y remodelación de la Cárcel-Presidio: Construcción de la Cuadra de Gendarmes.

Las obras a partir de esta fecha se concentraron en la ocupación de los espacios destinados a patios y en mejoras interiores de recintos ya existentes. En este sentido, en el interior del predio, exactamente en el patio mayor de la Alcaidía, se construyó, en el mes de enero de 1928, un recinto destinado al alojamiento de los gendarmes, tal como lo consigna la correspondencia interna de la institución ... con fecha de hoy se dio termino al nuevo departamento que se edificó por los penados de este penal para la cuadra de los gendarmes de este Destacamento, quedando compuesta dicha cuadra con una dimensión de diez metros de largo por seis metros de ancho, con capacidad para 30 camas (Gendarmería de

21 Este hecho consta en fotografías de la colección Scarpa desde 1921 a 1950. Archivos Museo Regional de
Prisiones, 1928, p. 15). Este se situó en el patio de la Alcaidía, entre las oficinas de esta última y la puerta interior del Juzgado (Gendarmería de Prisiones, 1928, p. 3) y su ejecución se insertó en lo que se entendió como los trabajos obligatorios de los recluidos, según lo indicado por el reglamento carcelario vigente.

Además se consignaron obras menores al interior de la Alcaidía también se arreglo el casino de los gendarmes, una sala para el cuerpo de abogados, una sala de espera para la visita de los penados y una oficina para el Cuerpo de Guardia, [...]. El dinero indicado alcanzó para todos estos arreglos por motivo que los trabajos fueron ejecutados por los mismos recluídos sin costo alguno, de lo que se dio cuenta a la Intendencia (Gendarmería de Prisiones, 1928, p. 15). Con esta intervención prácticamente desapareció la separación entre la Alcaidía y el cuerpo de celdas, permaneciendo aún un pequeño pasillo que daba continuidad al camino de ronda en su costado norte y permitía la comunicación del recinto carcelario con el Juzgado.

Por otro lado, en 1927 se menciona, en la correspondencia de la institución, la existencia de un patio de la cocina (Gendarmería de Prisiones, 1927, p. 150). Este, según la descripción del documento, se localizó en el costado poniente del exterior del cuerpo de celdas hacia calle Chiloé, constatación que reforzaría la suposición en cuanto a la ubicación de la cocina almacén en las obras ejecutadas en torno a 1903.

En cuanto a la fachada del conjunto, en esas fechas consta como intervención la apertura de una puerta (Fig. 3), junto al acceso principal del presidio, por medio de la cual se accedía a la zapatería del penal ${ }^{21}$. Este recinto fue el punto donde se efectuaban los encargos a los reos o se vendían los trabajos que estos realizaban, pero se trató también del único lugar por el que era posible ingresar al complejo carcelario sin estar recluido o sin tener relación con algún reo. Se constituyó así en la única instancia interior de visibilización de su existencia así como también de su vinculación con la comunidad. Esta puerta, junto con la comunicación que ofrecía, se

\footnotetext{
Magallanes y Sra. Josefina Díaz Vidal.
} 


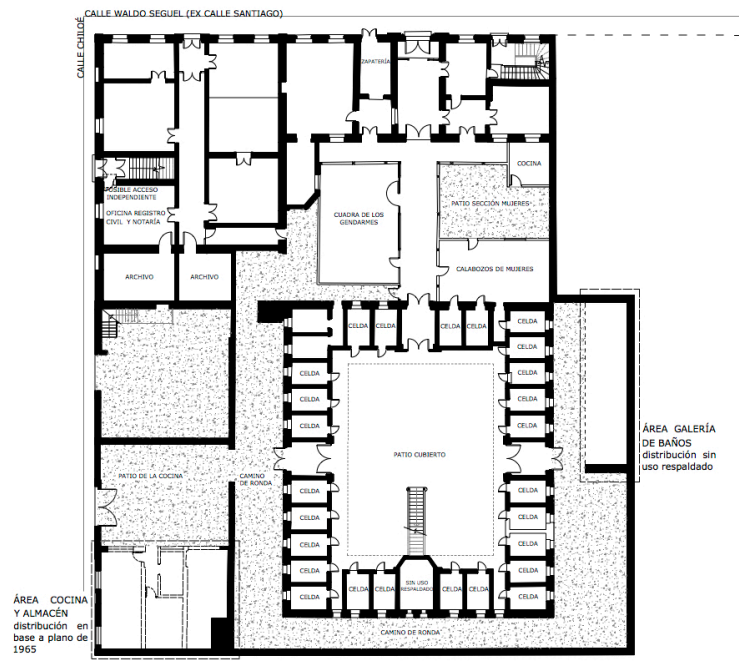

ETAPA DE 1928

PLANTA ARQUITECTURA

PRIMER NIVEL

CUADRA DE GENDARMES

ACCESO A ZAPATERÍA

Fuente:Interpretación de los autores, diarios El Comercio y El Magallanes (diversas fechas), Documentos Archivo Dirección Regional de Gendarmería de Chile (Región de Magallanes y Antártica Chilena), antecedentes del Concurso Nacional de Arquitectura. Anteproyecto Biblioteca Regional y Archivo Regional de Magallanes (Dirección de Regional de Magallanes (Dirección de Blbliotecas, Archivos y Museos, 2014), Fondo Fotografico Museo Regional de Magallanes (DIBAM), Archivo Fotográfico Histórico Patrimonial Instituto de la PatagoniaUniversidad de Magallanes.
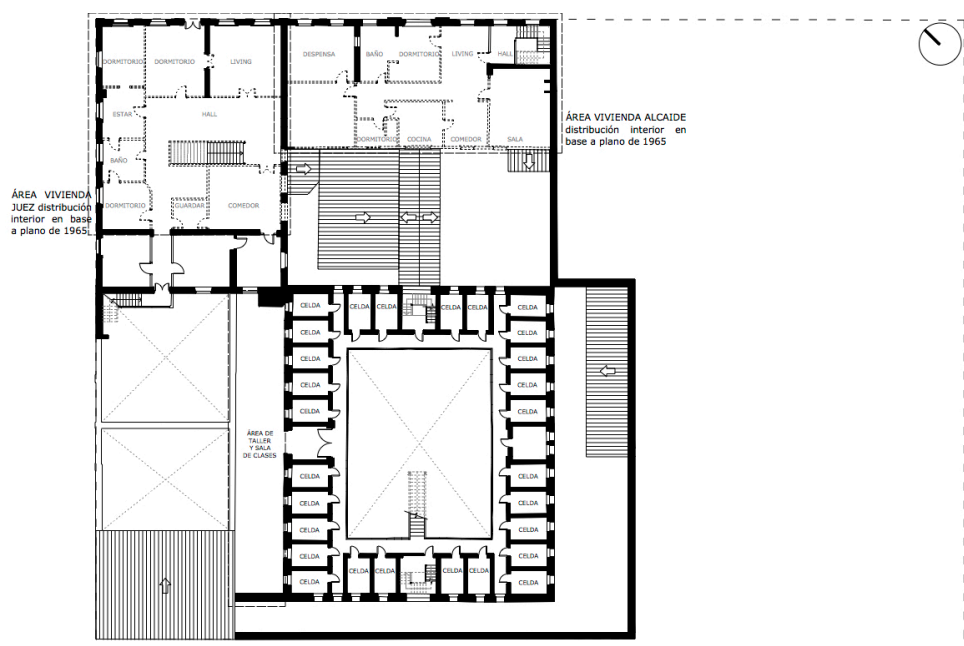

ETAPA DE 1928

PLANTA ARQUITECTURA SEGUNDO NIVEL

TALLER Y SALA DE CLASES

Fuente:Interpretación de los autores, diarios El Comercio y El Magallanes (diversas fechas), Documentos Archivo Dirección Regional de Gendarmería de Chile (Región de Magallanes y Antártica Chilena), antecedentes del Concurso Nacional de Arquitectura. Anteproyecto Biblioteca Regional y Archivo Regional de Magallanes (Dirección de Bibliotecas, Archivos y Museos, 2014), Fondo Fotográfico Museo Regional de Magallanes (DIBAM), Archivo Fotográfico Histórico Patrimonial Instituto de la PatagoniaUniversidad de Magallanes.

$\begin{array}{lllll}0 & 5 & 10 & 15 & 20\end{array} 25$

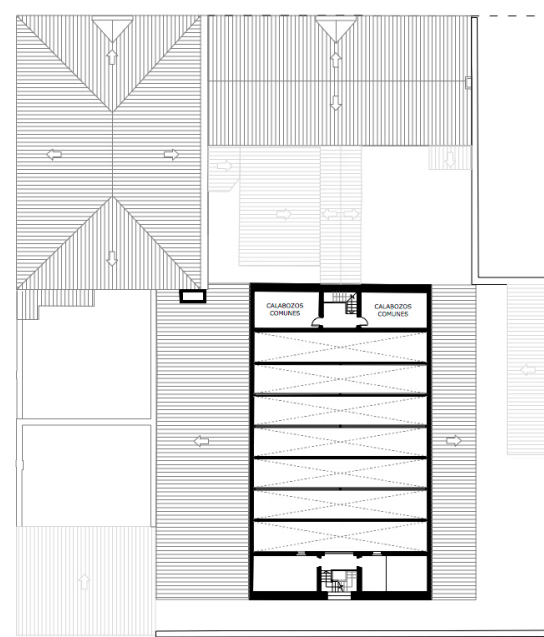

ETAPA DE 1928

PLANTA ARQUITECTURA TERCER NIVEL

Fuente:Interpretación de los autores, diarios El Comercio y El Magallanes (diversas fechas), Documentos Archivo Dirección Regional de Gendarmería de Chile (Región de Magallanes y Antártica Chilena), antecedentes del Concurso Nacional de Arquitectura. Anteproyecto Biblioteca Regional y Archivo Regional de Magallanes (Dirección de Bibliotecas, Archivos y Museos, Biblitecas, Archivos y Museos, Regional de Magallanes (DIBAM), Archivo Fotográfico Histórico Patrimonial Instituto de la Patagonia-
Universidad de Magallanes.

$\begin{array}{llllll}0 & 5 & 10 & 15 & 20 & 25\end{array}$ 
clausuró durante la década de 1950, volviéndose a la composición de fachada original.

Década de 1960: Ampliación de la Sección Celdas. Remodelación de la Cuadra de Gendarmes. Cierre del Camino de Ronda por Construcción de Sección Menores y por construcción de recintos Talleres y Marmita.

La existencia de una representación planimétrica en planta, fechada en $1965^{22}$, permitió establecer las modificaciones interiores del predio, transformaciones y cambios de uso, hacia esa fecha. En función de ello se logró establecer que, en el recinto carcelario, se utilizó el espacio denominado Camino de Ronda, específicamente las secciones situadas al oriente $\mathrm{y}$ poniente del volumen de celdas, para absorber el crecimiento del penal dado por la mejora en las condiciones de la reclusión. Se requirió disponer de espacios permanentes de alimentación, así como también se hizo necesario dar lugar a lo demandado por las nuevas normativas (Reglamento de Talleres particulares en 1944 y Reglamento sobre Normas Básicas para la Aplicación de una Política Penitenciaria Nacional de 1965) que, al explicitar la obligación de disponer de áreas de recreación y lugares adecuados para el funcionamiento de escuela, talleres o industrias anexas al establecimiento (León, 2008, p. 630), generaron presiones sobre el inmueble existente, que lentamente se fueron expresando en su arquitectura. La construcción, en la sección poniente del Camino de Ronda, de la Marmita y del recinto que probablemente fuera destinado a comedor, ambos en un primer nivel y de Talleres en el segundo nivel, sumado a la construcción, en el tramo opuesto del Camino de Ronda, de la Sección de Menores del recinto carcelario redundaron en la imposibilidad de circunvalar la sección de celdas para su vigilancia, así como produjeron el tapiado de las ventanas de celdas del primer nivel, por el lado oriente, y de las correspondientes a ambos niveles en su costado poniente. Por otro lado, se constató la construcción de un segundo nivel, ubicado entre el cuerpo de celdas y la Alcaidía, sobre lo que fuera la sección mujeres. Esta nueva superficie constó de

Fig. 3. Ciudad de Punta Arenas, en el extremo inferior derecho el complejo penitenciario judicial.

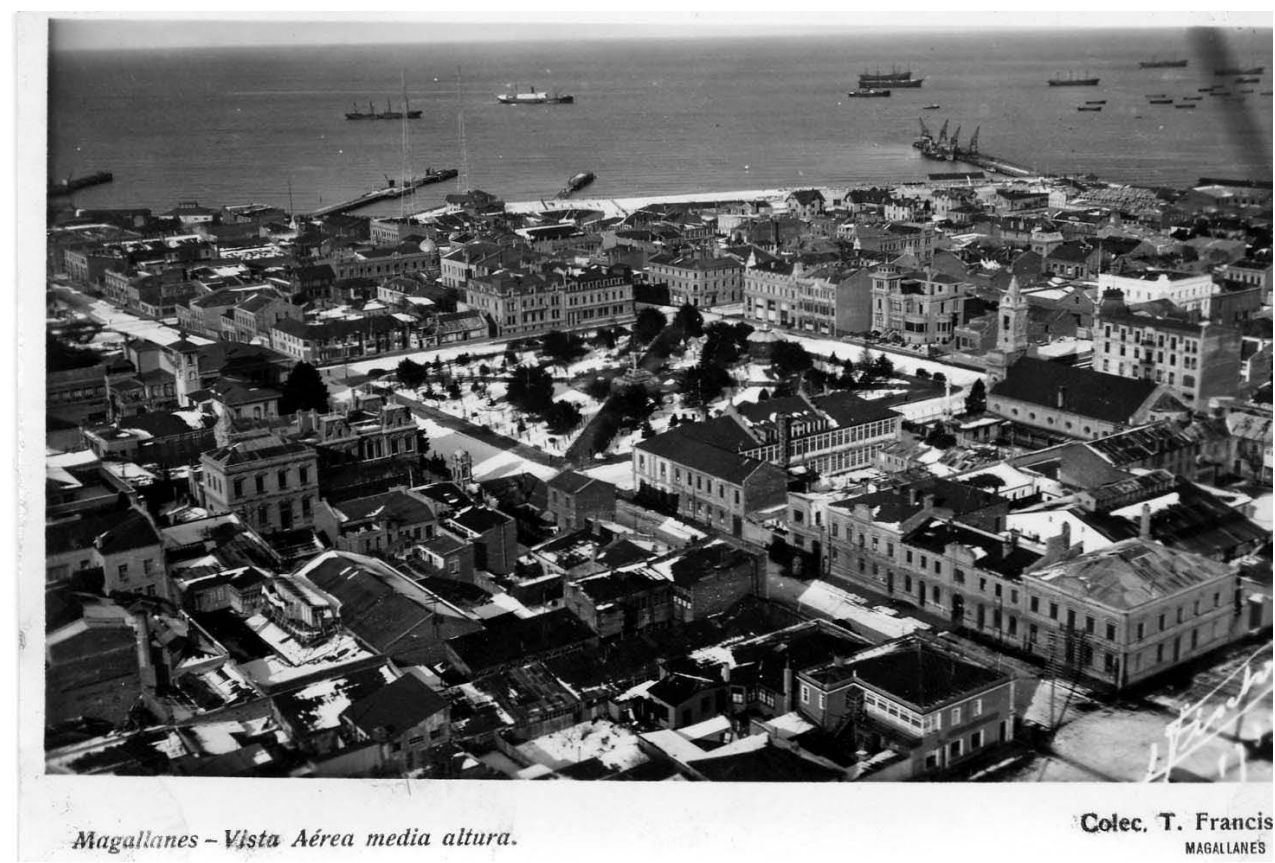

Fuente: Colección CEHA Archivo Fotográfico Histórico Armando Braun Menéndez UMAG IDP. 


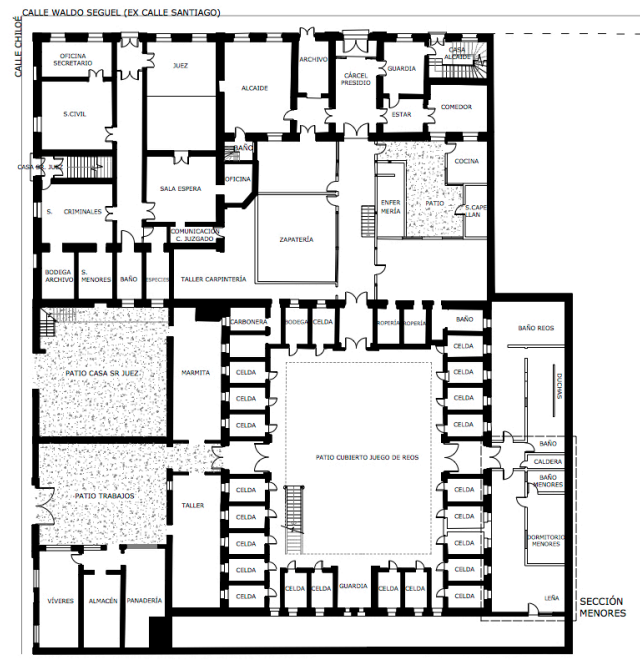

DÉCADA DE 1960

PLANTA ARQUITECTURA PRIMER NIVEL

REMODELACIÓN CUADRA GENDARMES SECCIÓN MENORES

TALLERES

MARMITA

REUBICACIÓN ESCALERA PRINCIPAL

Fuente:Interpretación de los autores, Documentos y Planimetría Archivo Dirección Regional de Gendarmería de Chile (Región de Magallanes y Antártica Chilena), Fondo Fotográfico Museo Regional de Magallanes (DIBAM) Archivo Fotográfico Histórico Patrimonial Instituto de la Magallanes, Álbum fotográfico Díaz Vidal.

\begin{tabular}{llllll}
$0 \quad 5$ & 10 & 15 & 20 & 25 \\
\hline
\end{tabular}
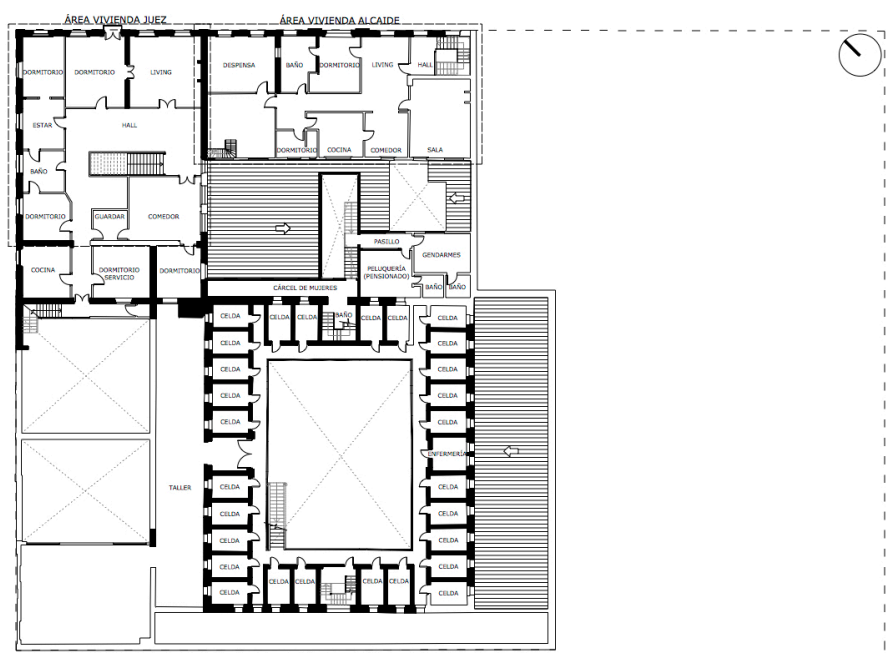

DÉCADA DE 1960

PLANTA ARQUITECTURA

SEGUNDO NIVEL

TALLERES

RECINTO GENDARMES

PELUQUERÍA

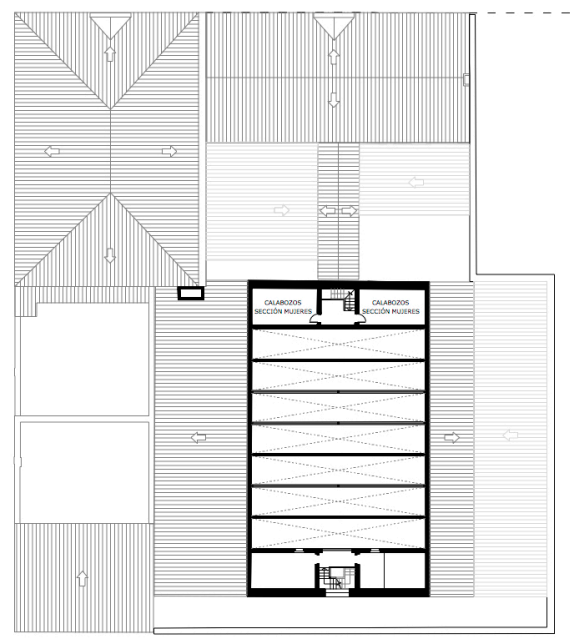

DÉCADA DE 1960

PLANTA ARQUITECTURA TERCER NIVEL

CALABOZOS SECCIÓN MUJERES

Fuente:Interpretación de los autores, Documentos $y$ Planimetría Archivo Dirección Regional de Gendarmería de Chile (Región de Magallanes y Antártica Chilena), Fondo Fotográfico Museo Regional de Magallanes (DIBAM), Archivo Fotográfico Histórico Patrimonial Instituto de la Patagonia- Universidad de Magallanes, Álbum fotográfico Díaz Vidal. $20 \quad 25$ 
dos recintos, una Peluquería y un estar con baño para los gendarmes.

Desde el punto de vista de los cambios de uso, el principal cambio trató del traslado de la sección mujeres, desde su ubicación inicial, en el patio de Alcaidía, hacia el tercer nivel del cuerpo central. Esto, probablemente debido al aumento de la demanda por espacio, requirió dar independencia al acceso a los recintos mencionados, ya no desde el segundo nivel del patio central, como fue construido inicialmente, sino desde el exterior de la sección celdas. Se construyó así una escalera en la galería de comunicación que vinculó directamente la Sección Mujeres con la Alcaidía. Además, se reacondicionó la antigua Cuadra de Gendarmes dividiéndola, para alojar un archivo y un taller de zapatería, y tras este, en el espacio remanente entre juzgado y cuerpo de celdas, un taller de carpintería.

En cuanto al cuerpo de celdas, que había permanecido sin modificaciones de importancia, cabe mencionar el desplazamiento hacia un costado de la escalera de madera del espacio central. Esta, que originalmente estuvo situada en el eje de simetría del conjunto, fue desplazada en estos años probablemente para dar un uso distinto al patio central. Este pasó así de denominarse Patio Cubierto a ser conocido primero como Patio Cubierto Juego de Reos y posteriormente como Patio Cubierto Multi-cancha, poniendo en evidencia los cambios en los usos otorgados al espacio central a partir del traslado de la escalera.

Décadas de 1980-1990: Remodelación y subdivisión de los espacios interiores del edificio. Readecuación de Juzgado y Casa del Juez a Sección Menores y Redestino a Dirección Regional de Gendarmería.

Las intervenciones realizadas al complejo en las décadas de 1980 y 1990 se caracterizaron por cambios de uso, subdivisión de recintos $y$ por el aumento en la carga de ocupación de los inmuebles, tanto por funcionarios como también por recluidos, lo que se puede establecer a partir de una representación planimétrica en planta de la modificación de redes de agua potable interior del

23 Penitenciaría de Punta Arenas (s.f.) Plano de Agua Potable. Planta. Escala 1:100. Punta Arenas.

24 Esta situación se aprecia en fotografía aérea del centro recinto ${ }^{23}$. Este documento, inédito y sin indicación de fecha, puede ser inscrito en el período en torno a 1980 por los proyectistas firmantes involucrados.

En 1984 el Ministerio de Obras Públicas, desarrolló una propuesta para la transformación del edificio del Juzgado en Sección menores del recinto carcelario y Dirección Regional de Gendarmería en parte del segundo nivel. El proyecto Readecuación Ex-Juzgados, Punta Arenas consideró la remodelación de las instalaciones para alojar veinticinco menores en el primer nivel y diecisiete en el segundo nivel. Esta intervención implicó la modificación de prácticamente la totalidad de las divisiones interiores y el cambio de sentido de uso del edificio, incluso llegando a clausurar el acceso principal al edificio situado en calle W. Seguel.

Cabe mencionar que el 24 de enero de 1975 el predio fiscal fue sido destinado al funcionamiento de la Penitenciaría Local, la destinación consideró el inmueble ubicado en la calle W. Seguel N625 (Arcadis Geotécnica, 2008, p. 60). El año siguiente se produjo el redestino del inmueble correspondiente al Juzgado de Letras, de calle W. Seguel N607, a Juzgados de Punta Arenas donde funcionaron hasta que en 1985 se redestinan a Dirección Regional de Gendarmería, que intervino el edificio, ajustándolo a sus requerimientos administrativos.

Por otro lado, a raíz de las intervenciones a partir de la década de 1960, con la construcción de prácticamente la totalidad del predio, emergió la necesidad de un control más efectivo del recinto. Fue así como esta vigilancia se trasladó, del otrora Camino de Ronda, a las cubiertas del complejo. Se construyeron de este modo, en torno a 1980, dos garitas de vigilancia, la primera situada en el extremo suroriente del predio y la segunda en el encuentro de las cubiertas del edificio del Juzgado y de celdas, consiguiéndose así una visión completa del perímetro del cuerpo de celdas del recinto carcelario. Este sistema de control se reforzó pocos años después, en fecha posterior a $1990^{24}$, con la construcción de una tercera garita sobre el recinto de panadería, en la esquina surponiente, cercano a calle Chiloé.

En cuanto a su perímetro, exteriormente se

urbano de la ciudad de Punta Arenas, publicada en el libro Punta Arenas. Siglo XX del autor Mateo Martinic (2013, p. 242). 


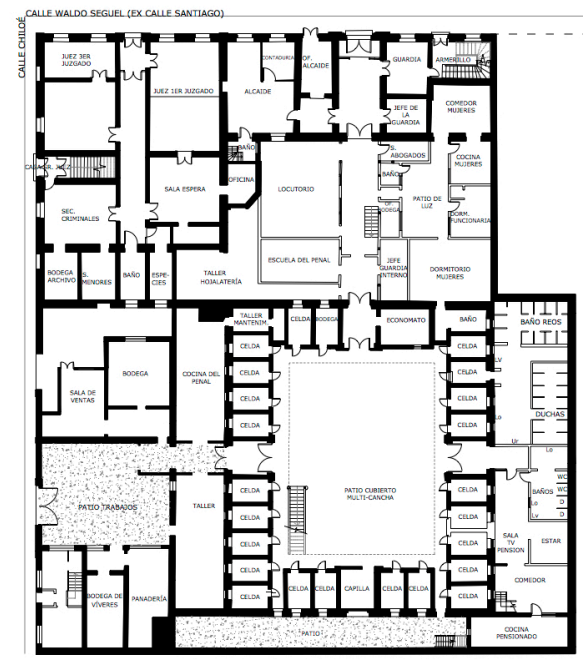

DÉCADAS DE 1980-1990

PLANTA ARQUITECTURA

PRIMER NIVEL

REMODELACIONES Y

SUBDIVISIONES INTERIORES

JUZGADO REDESTINO A GENDARMERÍA

Fuente:Interpretación de los autores, Documentos y Planimetría Archivo Dirección Regional de Gendarmería de Chile (Región de Magallanes y Antártica Chilena), antecedentes del Concurso Nacional de Arquitectura. Anteproyecto Biblioteca Regional y Archivo Regional de Magallanes (Dirección de Bibliotecas, Archivos y Museos, 2014), entrevistas Suboficiales Mayores de Gendarmería de Chile en retiro: Sr. José Nauto Torres, Sr. José Nail Inimán, Sr. José Mansilla Soto.

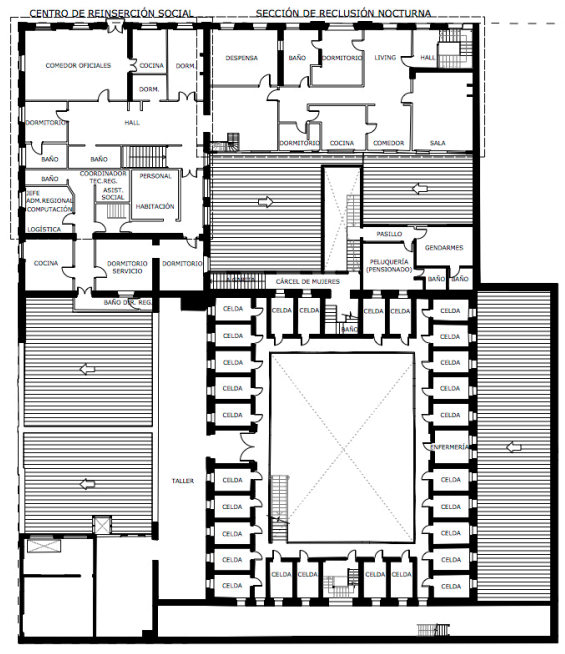

DÉCADAS DE 1980-1990 PLANTA ARQUITECTURA SEGUNDO NIVEL

CASA JUEZ REDESTINO A GENDARMERÍA SECCIÓN MENORES

RECLUSIÓN NOCTURNA

Fuente:Interpretación de los autores, Documentos y Planimetría Archivo Dirección Regional de Gendarmería de Chile (Región de Magallanes y de Chile (Región de Magallanes y
Antártica Chilena), antecedentes del Concurso Nacional de Arquitectura. Anteproyecto Biblioteca Regional y Archivo Regional de Magallanes (Dirección de Bibliotecas, Archivos y Museos, 2014), entrevistas Suboficiales Mayores de Gendarmería de Chile en retiro: $\mathrm{Sr}$. José Nauto Torres, Sr. José Nail Inimán, Sr. José Mansilla Soto.

$\begin{array}{llllll}0 & 5 & 10 & 15 & 20 & 25\end{array}$

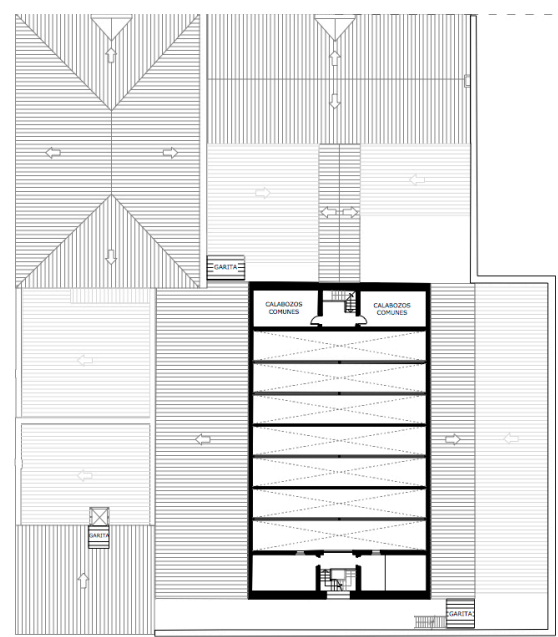

DÉCADAS DE 1980-1990 PLANTA ARQUITECTURA TERCER NIVEL

SECCIÓN CELDAS CÁRCEL-PRESIDIO

Fuente:Interpretación de los autores, Documentos y Planimetría Archivo Dirección Regional de Gendarmería de Chile (Región de Magallanes y Antártica Chilena), antecedentes del Concurso Nacional de Arquitectura. Anteproyecto Biblioteca Regional y Archivo Regional de Magallanes (Dirección de Bibliotecas, Archivos y Museos, 2014), entrevistas Museos, 2014), entrevistas Suboficiales Mayores de Gendarmería de Chile en retiro: Sr.
José Nauto Torres , Sr. José Nail Inimán, Sr. José Mansilla Soto.

$\begin{array}{llllll}0 & 5 & 10 & 15 & 20 & 25\end{array}$ 
mantuvieron inalteradas las fachadas, aún cuando en un momento indeterminado, posterior a 1974 , se eliminó el frontón que coronaba la fachada del Juzgado por calle W. Seguel.

\section{Etapa de cierre 2005-2015: Cierre definitivo y redestino a Archivo y Biblioteca Regional}

Entre la década de 1990 y el año 2015, fecha de cierre del inmueble de calle Waldo Seguel $N^{\circ} 607$, las principales modificaciones fueron de redistribuciones interiores o cambios de uso como resultado del aumento de la carga de uso de las instalaciones por el crecimiento de la institución carcelaria. En este sentido, en el año 1999, destacó la habilitación del entretecho del edificio de Juzgado y su compartimentación para su utilización como oficinas de la Dirección de Gendarmería. Esta modificación implicó disponer de $162 \mathrm{~m}^{2}$ ubicados, en la práctica, en una tercera planta, para la habilitación de oficinas según la propuesta establecida por el Sr. Carlos Lara Valenzuela, arquitecto del Subdepartamento de Infraestructura de Gendarmería de Chile (Gendarmería de Chile XII Región, 1999). Junto con esta modificación se consigna también la readecuación del segundo nivel del edificio de la Dirección Regional de Gendarmería para su utilización por parte de la Dirección y de alojamiento para oficiales de guardia. Dentro de estos antecedentes se evidencia, además, la habilitación del segundo piso de la Alcaidía, originalmente vivienda del Alcaide, como la sección de reclusión nocturna (Gendarmería de Chile XII Región, 1999).

Por otro lado, el 18 de Julio del 2003, a raíz del inicio de funciones del nuevo Complejo Penitenciario de la ciudad (Gendarmería de Chile XII Región, 2004), se produjo el traslado de la totalidad de los recluidos y actividades desde el edificio en uso al muevo recinto. Desde entonces se comienza a acoger en las instalaciones de la, a partir de ahí, antigua cárcel de la ciudad de una serie de actividades de índole cultural y de entretenimiento. Como consecuencia, por Res. Exenta N³87 del 22.08.2005 de la Secretaría Regional Ministerial de Bienes Nacionales de la Región de Magallanes y Antártica Chilena, se decretó la ampliación de destino del inmueble para actividades culturales, estableciendo el cierre del recinto en su dimensión carcelaria. Posteriormente, según Decreto N409 del 28.10.2009, el conjunto edilicio, constituido por la Dirección Regional de Gendarmería, la Prefectura de Carabineros y la Penitenciaría local, fue declarado por el Consejo de Monumentos Nacionales, como Monumento Nacional en su categoría Monumento Histórico (MMNN, 2009).

$\mathrm{Si}$ bien el edificio ya no se encontraba en operación como centro de reclusión, si se mantuvo en uso en su dimensión administrativa. La Dirección Regional de Gendarmería de Chile continuó utilizando el resto de dependencias hasta la fecha real de abandono de las instalaciones, producida a mediados del año 2015 (La Prensa Austral, 2015).

\section{CONCLUSIONES}

La arquitectura de las cárceles y prisiones constituyen temáticas poco abordadas tanto por la disciplina como por las historias de la arquitectura. Más aún, los conocimientos que se pueden tener respecto a la arquitectura de los lugares de corrección toman puntos de vista históricos y remiten a las ideas y paradigmas en que se basan, a proyectos usualmente no ejecutados, amén de restricciones presupuestarias o ajustes determinados por los emplazamientos, rara vez podemos contar con derroteros más o menos precisos de su evolución. Además, como en pocos tipos de edificios opera en la arquitectura carcelaria una contradicción dado el escaso conocimiento que se puede tener sobre su régimen interno, su funcionamiento o las relaciones entre sus recintos $y$, al mismo tiempo, dada la necesidad de contar con lugares de castigo y corrección capaces de articular aspectos sociales y judiciales que operan a través del sistema penitenciario y sus dispositivos espaciales, funcionales y formales. En ese sentido, se buscó dar cuenta de las diferentes etapas por las que el complejo penitenciario y judicial de Punta Arenas atravesó a lo largo de su historia, tratando de entender el estado actual de su arquitectura.

Fue así que la reconstrucción planimétrica elaborada, evidenció la ausencia de las reflexiones teóricas y de doctrinas que habían inspirado los referentes de la arquitectura penitenciaria europea basados en el modelo Panóptico de Bentham o en modelo en peine de la prisión de Fresnes, puesto que 
el partido adoptado se encontró determinado por la decisión de construir edificios discretos ubicados en una fracción de manzana del área central de la ciudad, justo ahí donde se anclaban y consolidaban los poderes políticos, religiosos y económicos, además de las residencias de la incipiente burguesía local de la región. Al respecto es posible realizar dos observaciones, una primera en relación a la arquitectura del edificio, específicamente a las decisiones adoptadas por el proyectista original en lo referido al partido espacial y las funciones del edificio; y una segunda en relación a su localización en la ciudad.

En relación al partido espacial del conjunto en ese cuarto de manzana, se debe considerar que se trata de tres predios diferenciados, el primero, del Cuartel de Policía que aquí no se analiza, el segundo asociado a la Cárcel-Presidio y el tercero correspondiente al Juzgado de Letras, cuyos destinos ya se encontraban fijados a fines del siglo XIX y donde se materializarían de manera tardía esa serie de obras públicas impulsadas bajo la presidencia de J. M. Balmaceda, coincidentes con un período de auge de la ciudad. Se debe considerar también que, siguiendo a Von Christmar (1929), a excepción de la Cárcel y Juzgados de Santiago, la arquitectura penitenciaria chilena unificó los recintos de administración de justicia y reclusión recién durante las primeras tres décadas del siglo $\mathrm{XX}$. Por ambas razones, no sería posible entender al complejo penitenciario y judicial de Punta Arenas como resultado de una integrada solución espacial y funcional. Contrariamente, habría que partir de la idea que se trató de edificios situados en predios diferentes, que dieron respuesta a necesidades distintas, pero que coincidieron en un momento de la historia de la ciudad, aquel en que se movilizaron vectores económicos, demográficos y sociales que la dinamizaron.

Las variaciones concernientes al Juzgado de Letras y la vivienda del juez fueron escasas, y habría que remitirlas a los procesos de adaptación que el espacio de residencia sufrió, primero por el cambio de destino del segundo piso del inmueble al ser desafectado como lugar de habitación y transformarse, primero en asiento de un segundo juzgado, luego como parte de la Dirección Regional de Gendarmería de Chile. Las variaciones y transformaciones de la Cárcel-Presidio son de otra naturaleza y se encuentran determinadas fundamentalmente por funciones que, en un inicio no fueron consideradas, $y$, peor aún, difícilmente pudieron ser articuladas con funciones y recintos ya existentes, lo que llevó a través de las décadas a ocupar el poco espacio libre disponible de la parcela.

Desde un punto de vista arquitectónico, las ampliaciones y modificaciones comprometieron dos aspectos relevantes de la arquitectura original; en primer lugar el eje establecido desde la ex calle Santiago hasta la sección de celdas, y en segundo lugar el camino de ronda, necesario por razones de seguridad. Yuxtaponer volúmenes dislocó las circulaciones del recinto penitenciario y suprimió los patios interiores, sacrificando con ello los espacios que permitían la iluminación y ventilación natural al interior de la cárcel. En este sentido, las observaciones constatadas han hecho evidente que en la evolución del complejo no se previeron los requerimientos nacidos de la complejización de la actividad carcelaria, del aumento de demanda o de la reflexión en cuanto a su rol.

Finalmente, respecto a su localización, no es de extrañar que el Juzgado de Letras ocupara una posición en esquina de la ciudad, distante a 100 metros de la Plaza de Armas de la ciudad, complementando la presencia del Estado en el área central de la urbe. La ubicación permitió resolver astutamente el problema funcional que supuso tener en un mismo edificio tanto la vivienda del juez, como el asiento judicial, que además requiere utilizar dispositivos simbólicos en su acceso, al establecer entradas diferenciadas por calles Chiloé y W. Seguel para una y otra función. Partiendo de la misma base argumental, la posición de la Cárcel-Presidio resulta extraña, en Santiago tanto la Penitenciaría como la Cárcel Pública fueron construidas en la periferia de la ciudad, mientras que en Punta Arenas, tal y como había ocurrido previamente, el lugar de corrección y castigo ocupó hasta inicios del siglo XXI una posición central. Combessie ha señalado que la localización de las prisiones perturbó los centros de las ciudades por su sola presencia y relaciones de cercanía establecidas en el vecindario (2002, p.72), motivando su traslado, cambio de destino y, en paralelo, estrategias de demolición, restauración o rehabilitación, cuestiones a las que el complejo 
penitenciario y judicial no ha estado ajeno, pero al menos si a resguardo dada su condición de Monumento Histórico.

\section{BIBLIOGRAFÍA}

a) Inéditas

Gendarmería de Prisiones (1904). Copiador de notas al juzgado de 1904 a 1906.

Gendarmería de Prisiones (1911). Estadística de Reos Salidos. Empezado el 8 de Enero de 1910. Terminado el 31 de Diciembre de 1911

Gendarmería de Prisiones (1927). Libro de Guardia de Prevención.

Gendarmería de Prisiones (1928). Copiador de oficios enviados a la comandancia del cuerpo de Gendarmeria de Prisiones de Santiago.

Gendarmería de Prisiones (1929). Libro de la Porteria Carabineros de Chile.

Informe Nro. 41 de la Gobernación del Territorio, a la Dirección de Obras Públicas del Ministerio de Industria i Obras Públicas, 24 de noviembre 1898.Archivo Nacional Histórico de Chile, Fondo Ministerio de Obras Públicas, Volumen 999

\section{b) Impresas}

Altmann, J. (1970). Arquitectura Penitenciaria. Derecho, 28, 56-77

Arcadis Geotécnica (2008). Consultoría de medición de variables territoriales, estudio de cabida y propuesta de gestión: inmueble fiscal penitenciario de Punta Arenas. Recuperado de http://www.goremagallanes. $\mathrm{cl} /$ sitioweb/ESTUDIOS/bienes_nacionales.php.

Baeriswyl, D. (2001). Arquitectura en Punta Arenas: Primeras edificaciones en ladrillos: 1892-1935. Punta Arenas, Chile: La Prensa Austral.

Baltard, L. (1829). Architetonographie des prisons u parallèle des divers systèmes de distribution dont les prisons sont susceptibles, selon le nombre et la nature de leur population, l'étendue et la forme des terrains, Palais des Beaux-Arts, París

Bentham, J. (1979). El Panóptico, Madrid, Ediciones de la Piqueta.

Cárcel (1902, 26 de julio). El Comercio, p.2

Cárcel de Magallanes (1899, 23 de marzo). El Magallanes, p. s.n.

Cárcel en construccion (1902, 1 de agosto). El Comercio, p.2
Cárcel i Cuartel de Policia en construcción. (1899, 17 de diciembre). El Magallanes, p. s.n.

Cárcel Pública. (1910, 19 de julio). El Magallanes, p. s.n.

Caro, F. (2011, 09 de septiembre). Arquitectura Penitenciaria: desde su génesis a las nuevas tecnologías de investigación criminal. Crítica. Revista latinoamericana de ensayo. Recuperado de http://www.critica.cl

Caro, F. (2013). John Howard y su influencia en la reforma penitenciaria europea de finales del Siglo XVIII. Eguzkilore, 27, 149-168

Cecarelli, S. (2009). El penal fueguino. Origen del Estado y la Sociedad en la frontera austral Argentina (1895 1916). Ushuaia: Editorial Utopias.

Cisternas, J. (1998). Historia de la Cárcel Penitenciaria de Santiago 1847-1887. La Implementación del Sistema Penitenciario en Chile. Santiago: Edición de la Dirección nacional de Gendarmería de Chile.

Combessie, P. (2002). La ville et la prison une troublante cohabitation. Revue Projet, 1(269), 70-76

Comisión de Alcaldes (1914) Actas de sesiones Año 1913. Punta Arenas: Imprenta Chile Austral

Compañía Arauco (1902, 9 de abril). El Comercio, p.2

De cuartel (1902, 18 de marzo). El Comercio, p.2

Dirección de Bibliotecas, Archivos y Museos (2014). Concurso Nacional de Arquitectura. Anteproyecto Biblioteca Regional y Archivo Regional de Magallanes. Recuperado de http://www.concursomagallanesbrar.cl Edificacion fiscal. (1906, 28 de abril). El Magallanes, p. s.n.

Edificio de la cárcel (1900, 11 de Febrero) El Magallanes, p. s.n.

Edificio de la nueva cárcel (1903, 1 de octubre). El Comercio, p.2

Foucault, M. (2008). Vigilar y castigar. Nacimiento de la prisión. Buenos Aires: Siglo XXI Editores.

García, C. (2012), Diseño y Ambiente Institucional ¿Hacia dónde va la Arquitectura Penitenciaria? En: VVAA, Memoria $1^{\circ}$ Seminario de Arquitectura Penal para una Reinserción Social. Hacia una búsqueda de un Diseño Cualitativo y Funcional dentro de un Marco Normativo (pp.36-45) Concepción: Impresora Ícaro

Gutiérrez, R. (1997). Arquitectura y urbanismo en Iberoamérica. Madrid: Ediciones Cátedra

Gendarmería de Chile XII Región (2004). Historia Penitenciaria en la Región de Magallanes.

Gendarmería de Chile XII Región (1999). Necesidades de Planta Física (Oficio Ord. N¹2.00.00. 420/99)

Inauguraron farmacia y policlínico en edificio de Gendarmería. (2015, 7 de diciembre). La Prensa Austral. Recuperado 
de http://laprensaaustral.cl/cronica/inauguraronfarmacia-y-policlinico-en-edificio-de-gendarmeria/

León, M. A. (1998). Entre el espectáculo y el escarmiento: El presidio ambulante en Chile (1836-1847). Historia, 31, 147-177

León, M. A. (1999). Acercamientos a la realidad penal de Magallanes. Punta Arenas y la progresiva configuración de una estructura carcelaria. En: Actas IV Congreso de Historia de Magallanes. (pp. 165-183) Punta Arenas, Chile: Parenazon Chile Ltda.

León, M. A. (2003). Encierro y corrección: la configuración de un sistema de prisiones en Chile 1800-1911. Santiago: Universidad Central de Chile, Facultad de Ciencias Jurídicas y Sociales. 3 v. (1019 p.)

León, M. A. (2008). Documentos para la historia de las prisiones en Chile en el siglo XX: (1911-1965), Revista chilena de historia del derecho, 20, 371-631

León, M. (2014). Por una "necesidad de preservación social": Cesare Lombroso y la construcción de un "Homo criminalis" en Chile (1880-1920). Cuadernos de Historia, 40, 31-59

Martinic, M. (2006). Historia de la Región Magallánica. Punta Arenas: Ediciones Universidad de Magallanes.

Martinic, M. (2013). Punta Arenas Siglo XX. Punta Arenas: Ediciones GEOPARK.

Martinovic, D. (2006). Penal de Magallanes: Una oscura y desconocida colonización. En: Actas $V$ Congreso de Historia de Magallanes (pp.114-127). Punta Arenas, Chile: Impresos Vanic.

Martinovic, D. (2007). Colonización Penal de Magallanes. (Tesis de pregrado). Universidad de Magallanes, Punta Arenas, Chile.

Melossi, D., \& Pavarino, M. (2014). Cárcel y Fábrica. Los orígenes del sistema penitenciario (siglos XVI y XIX), México: Siglo Veintiuno Editores.

Ministerio de Industria y Obras Públicas (1898-1899). Edificios Públicos. Notas y Antecedentes Varios. 1898-1899.

Monumentos Nacionales (2009). Decreto N409 del día 28 de Octubre de 2009.

Navarro, L. (1908). Censo jeneral de población i edificación, industria, ganadería i minería del territorio de Magallanes República de Chile : levantado por acuerdo de la comisión de alcaldes el día 8 de setiembre de 1906, pasado y presente del territorio de Magallanes. Tomo II. Talleres de la Imprenta de El Magallanes

Nuevas construcciones. (1905, 28 de Julio). El Magallanes, p. s.n.

Palma, D. (2011). Ladrones. Historia social y cultura del robo en Chile, 1870-1920. Santiago: LOM Ediciones

Penitenciaría de Punta Arenas (s.f.) Plano de Agua Potable. Planta. Escala 1:100. Punta Arenas

Pietrogrande, H. (1898). Plano de Punta Arenas 1898. Escala 1:8000. Punta Arenas.

Raffa, C. (2007). El modelo panóptico en la arquitectura penitenciaria argentina: la primera cárcel en la ciudad. Mendoza, 1864. Argos, 24(47), 15-27

Ramírez, L. (1998). Historia Penitenciaria. Una recopilación de la función penitenciaria hasta 1943. Chile: Talleres Gráficos de Gendarmería de Chile.

Saldivia, Z., \& Caro, F. (2010). Alcances sobre el Modelo Panóptico en la Arquitectura Penitenciaria y Médica Chilena. Latin American Journal of International Affairs, 2(3), 23-46

Se ha postergado. (1902, 22 de febrero). El Comercio, p. 2

Secretaría Regional Ministerial de Bienes Nacionales de la Región de Magallanes y Antártica Chilena (2005) Resolución Exenta N³87.

Servicio de Prisiones (1965). Punta Arenas. Cárcel presidio. Plano de Planta. 1:100. Santiago

Terminación del Edificio del Juzgado. (1910, 19 de mayo). El Magallanes, p. s.n.

Trabajos en la cárcel. (1904, 15 de diciembre). El Magallanes, p. s.n.

Ulloa, F. (1879). La Penitenciaría de Santiago. Lo que ha sido, lo que es i lo que debería ser. Santiago: Imprenta de Los Tiempos.

Valles, M. (1999). Técnicas cualitativas de investigación social. Reflexión metodológica y práctica profesional. Madrid: Editorial Síntesis, S.A.

Vidler, A. (1995). L'espace des lumieres. Architecture et philosophie de Ledoux à Fourier. Paris: Picard

Von Christmar, E. (1929). Estudio sobre sistema penitenciarios y construcciones para prisiones. Anales del Instituto de Ingenieros de Chile, 11, 689-721

c) Entrevistas:

Víctor Fuentes Morales, Dir. Regional de Gendarmería, Coronel de Gendarmería de Chile, 8 de julio de 2015.

José Nauto Torres, Suboficial Mayor de Gendarmería de Chile en retiro, 23 de octubre de 2015.

José Nail Inimán, Suboficial Mayor de Gendarmería de Chile en retiro, 23 de octubre de 2015.

José Mansilla Soto, Suboficial Mayor de Gendarmería de Chile en retiro, 23 de octubre de 2015.

Jorge Hernández Paredes, Jefe Administrativo, Dirección Regional de Gendarmería de Chile, 18 de enero de 
2016.

Eric Escobar Cerda, Coord. de Infraestructura, Dirección Regional de Gendarmería de Chile, 18 de enero de 2016.

Juan Escobar Zepeda, Fiscal Corte Suprema, 21 de abril de
2016. Juez del $1^{\circ}$ Juzgado de Letras de Punta Arenas desde el 29 de junio de 1979 hasta el 20 de julio de 1983; Fiscal de Corte de Apelaciones de Punta Arenas desde el 21 de julio de 1983 hasta el 16 de octubre de 1992. 